\title{
Modeling Mediterranean Ocean climate of the Last Glacial Maximum
}

\section{U. Mikolajewicz}

Max-Planck-Institut für Meteorologie, Bundesstr. 53, 20146 Hamburg, Germany

Received: 25 August 2010 - Published in Clim. Past Discuss.: 1 October 2010

Revised: 24 January 2011 - Accepted: 26 January 2011 - Published: 3 March 2011

\begin{abstract}
A regional ocean general circulation model of the Mediterranean is used to study the climate of the Last Glacial Maximum. The atmospheric forcing for these simulations has been derived from simulations with an atmospheric general circulation model, which in turn was forced with surface conditions from a coarse resolution earth system model. The model is successful in reproducing the general patterns of reconstructed sea surface temperature anomalies with the strongest cooling in summer in the northwestern Mediterranean and weak cooling in the Levantine, although the model underestimates the extent of the summer cooling in the western Mediterranean. However, there is a strong vertical gradient associated with this pattern of summer cooling, which makes the comparison with reconstructions complicated. The exchange with the Atlantic is decreased to roughly one half of its present value, which can be explained by the shallower Strait of Gibraltar as a consequence of lower global sea level. This reduced exchange causes a strong increase of salinity in the Mediterranean in spite of reduced net evaporation.
\end{abstract}

\section{Introduction}

The Mediterranean is a semi-enclosed basin connected with the Atlantic by the narrow and shallow Strait of Gibraltar. It is an evaporative basin characterized by an anti-estuarine circulation with active deep water formation. It is influenced by both the monsoon circulation as well as the European climate.

The Last Glacial Maximum (LGM) around 21 kyr B.P. is a well studied time slice with a glacial climate substantially different from present climate. The first regional re-

Correspondence to: U. Mikolajewicz (uwe.mikolajewicz@zmaw.de) construction of LGM sea surface temperature (SST) from assemblages of foraminifera in the Mediterranean (Thiede, 1978) showed a marked difference in the cooling between eastern and western Mediterranean: the cooling in the northwestern Mediterranean was much stronger than in the eastern Mediterranean. Thiede also showed the presence of a cool fresh tongue in the Levantine originating from the Aegean. A recent reconstruction (Hayes et al., 2005) essentially confirmed the strong gradient in the climate signal between eastern and western Mediterranean, but did not find the cold fresh tongue. They found the strongest cooling in the northwestern Mediterranean in summer, whereas the cooling in the Levantine was small. Temperature estimates from alkenone unsaturation, however, indicate quite strong cooling (approx. 10 K) in the eastern Mediterranean (e.g. Emeis et al., 2003; Almogi-Labin et al., 2009), which conflicts with the weak cooling reported from assemblages of foraminifera. A comprehensive overview over the knowledge about the state of the Mediterranean at LGM can be found in Robinson et al. (2006).

Due to the lower sea level, the sill depth of the Strait of Gibraltar was reduced at LGM. This would, under the assumption of hydraulic control, result in reduced exchange rates between Atlantic and Mediterranean (e.g. Bryden and Stommel, 1984; Rohling and Bryden, 1994), which in turn would lead to higher salinity in the Mediterranean, which is consistent with geological evidence (e.g. Thunell and Williams, 1989).

Although the Mediterranean is an almost ideal region for regional ocean modeling due to the very limited exchange with the Atlantic, only very few attempts have been made to simulate the glacial circulation. Bigg (1994) used a regional ocean model forced with surface fluxes calculated interactively from bulk formulas with atmospheric input data derived from simulations with a coarse-resolution atmosphereonly model. The results suffered from short-comings of the atmospheric forcing and the ocean climate. Whereas this

Published by Copernicus Publications on behalf of the European Geosciences Union. 
approach led to a substantial cooler climate, the effect on salinity was rather small, which might be an artifact due the short simulation period.

Myers et al. (1998) used a regional ocean general circulation model (GCM) with a rather realistic climate to investigate changes in deep water and ocean circulation. Their approach to LGM surface forcing was completely different than Bigg's approach: reconstructed SST and sea surface salinity (SSS) anomalies were added onto the climatological present days SST and SSS. These values were used as model forcing using a restoring boundary condition. Their prescribed salinity anomalies were always strongest in the eastern Levantine. Their model responded to these changes in thermohaline forcing with an eastward shift of the deep water formation in the eastern basin from the Adriatic to the Rhodes gyre. In the western basin the location of deep water formation did not change substantially.

The model study presented here follows a similar approach as the study of Bigg (1994). A regional ocean model is forced with atmospheric input data from high-resolution atmospheric model simulations. River input and Atlantic hydrography are modified as well according to model results. Except from the ice sheet extent, the atmospheric composition and global sea level, no reconstructions enter the model. This method has the advantage that the model results are completely independent from e.g. SST reconstructions, which allows to use these data for the validation of the model results.

The goal of this study is to simulate the ocean climate and the circulation of the Mediterranean during the LGM with a dynamic downscaling approach. An important aspect is to reproduce and understand the characteristic pattern of change in SST, which is known from reconstructions. In Sect. 2 of this paper the model and forcing are described. The climate of the control run is described and compared to observational estimates in Sect. 3. The setup for the LGM is described in Sect. 4 and the results for this time slice in Sect. 5.

\section{Model and forcing}

The model used in this study is a regional version of the primitive equation ocean general circulation model MPIOM (Max-Planck-Institute ocean model, Maier-Reimer, 1997; Marsland, 2003). The model covers the entire Mediterranean, the Black Sea and a small Atlantic box with a mean horizontal resolution of $20 \mathrm{~km}$. The resolution is sufficient for some eddy variability to occur in the model. The topography of the model is shown in Fig. 1. The model has 29 unevenly spaced vertical levels, 8 of them in the top $100 \mathrm{~m}$, and uses partial cells at the bottom. The model has a free surface. In order to prescribe the properties of the inflowing Atlantic water, a sponge zone with restoring of temperature and salinity to monthly climatological hydrography is applied at the western margin of the Atlantic box.

\section{Topography}
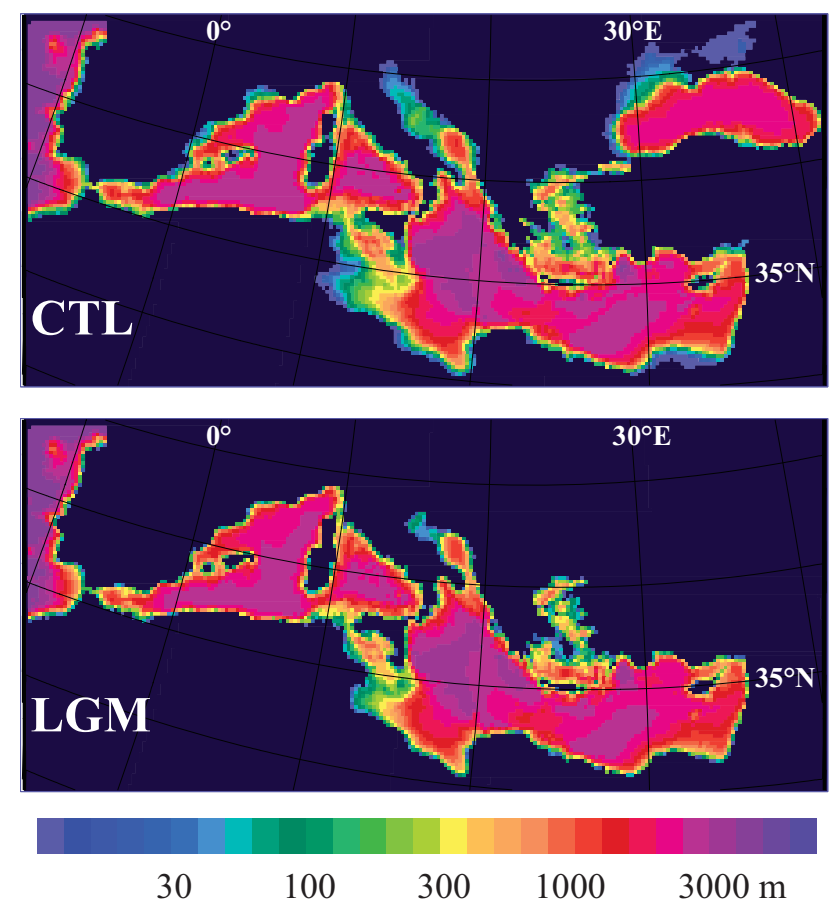

Fig. 1. Model topography in m for CTL (top) and LGM (bottom). Geographical coordinates are drawn for every $10^{\circ}$ in longitude and $5^{\circ}$ in latitude.

Heat fluxes at the surface are calculated using standard bulk-formulas with prescribed atmospheric forcing values and model SST. Prescribed input parameters are daily values of near-surface air temperature, dew point temperature, wind speed and downward radiative fluxes (shortwave and longwave). The upward longwave radiation is calculated from the model SST. The penetration of shortwave radiation into the ocean is set according to Jerlov optical water types Ib in the Mediterranean and III in the Black Sea (Jerlov, 1976).

Freshwater fluxes are calculated from prescribed daily precipitation and monthly climatological river runoff. Evaporation is determined from the interactively calculated latent heat flux. The model uses a mass flux boundary condition for freshwater fluxes. As the Mediterranean is an evaporative basin, sea level would sink continuously. This is prevented by weakly restoring the sea level at the westernmost grid points of the Atlantic box towards zero. Wind stress is prescribed directly.

The atmospheric forcing has been derived from time slice simulations with the atmospheric general circulation model ECHAM5 (Roeckner et al., 2003). The spectral model has been run in a horizontal resolution of T106 (approximately $1.125^{\circ}$ resolution on a Gaussian grid) with 39 vertical levels. SST, sea ice and vegetation distribution were derived from steady state simulations with a coarse resolution earth 
system model (ESM, Mikolajewicz et al., 2007). SSTs were corrected for systematic biases. Details of the procedure can be found in Arpe et al. (2011).

Two simulations were carried out (Arpe et al., 2011). One simulation represents a preindustrial climate (insolation corresponding to 1950, atmospheric partial pressure of $\mathrm{CO}_{2}$ of $280 \mathrm{ppm}$ ) with present topography and glacier distribution. The other simulation represents the state of the LGM with topography and ice sheet according to the ICE-5G reconstruction (Peltier, 2004). Other important modifications include insolation (according to $21 \mathrm{kyr}$ B.P.) and atmospheric composition ( $p \mathrm{CO}_{2}$ of $\left.185 \mathrm{ppm}\right)$. The simulations closely follow the PMIP2 protocol (Braconnot et al., 2007).

From these simulations, 20 years of daily atmospheric forcing were derived for each experiment through bilinear interpolation onto the grid of the ocean model. Land points of the atmospheric model were excluded from this interpolation. The forcing thus contains daily and interannual variability and is applied repetitively. A monthly river runoff climatology was derived from these simulations using a hydrological discharge model (Hagemann and Dümenil-Gates, 2003). The model used river masks adapted to the respective topographies for the two time slices. For the Mediterranean, however, these changes were basically restricted to regions like the Adriatic, where the coastline strongly differed due to to lower global sea level.

Compared with observations, this approach leads to a strong overestimation of the Nile discharge. The main causes for this are an overestimation of the precipitation in the source regions of the Nile as well as the neglect of evaporation from the rivers during their way towards the Mediterranean Sea. Once the surface module of the atmospheric model has calculated a runoff (either surface or deep drainage), it is transferred to the hydrological discharge model. The model transfers the discharge to the coast, but an evaporative loss is not permitted. Thus the calculated runoff of the Nile is $9700 \mathrm{~m}^{3} \mathrm{~s}^{-1}$. Ludwig et al. (2009) report that more than half of the water generated by surface runoff is lost. Only approximately $40 \%$ of the water reach Aswan. The observed runoff from the Nile prior to the Aswan Dam is $2900 \mathrm{~m}^{3} \mathrm{~s}^{-1}$ (calculated from Vörösmarty et al., 1998). However, as this value also represents some effects of irrigation, it was decided to use a simple correction of $50 \%$ for the purpose of this study. For consistency, this correction was applied in the LGM simulation as well.

All simulations were started from homogeneous water with $38 \%$ and $20^{\circ} \mathrm{C}$. For the Black Sea an initial salinity of $20 \%$ was used. A model initialization with relative light homogeneous water has the advantage, compared to initialization with climatology, that it guarantees that all the water masses found in the model have been produced by the model and are not remains of the initial conditions, as less dense bottom waters are easily replaced by dense surface waters.

During the spin up, minor corrections were made in the parameterizations, e.g. the first 99 years of the simulations were run with the full Nile discharge. However, all simulations have been run at least 400 years without any changes. The length of the simulations was different. Figures shown in this paper represent an average over the last 100 years of the simulations.

\section{Climate of the control simulation}

The approach used here is, with a few exceptions, based on modeled input data. The comparison of the simulated model climate with observed ocean climate allows to assess both the quality of the model and of the model forcing. The deviation of the climate of the control simulation (CTL) from the observed state of the Mediterranean yields at least a rough estimate of the quality of the simulated LGM climate. This would not have been possible, if only anomalies would have been used. The general approach is essentially similar to the approach of Bigg (1994). Bigg, however, used much coarser models, both for the ocean as well as for the atmospheric model, which was used to derive the atmospheric forcing for the ocean model.

For CTL, the model was integrated for 1999 years with the forcing derived from the preindustrial present day simulation of the atmospheric GCM. The remaining drift is negligible, except for the Black Sea, where the drift towards higher salinity is still substantial: $0.07 \%$ /century almost independent of depth.

This section deals with the assessment of the ability of the model to simulate some key parameters of the Mediterranean ocean climate, when driven with a forcing derived from the present day preindustrial simulation of the atmosphere model. This simulation will in the following be used as control simulation for the LGM simulation. It is assumed here that the potential effect of anthropogenic climate change on the Mediterranean ocean climate, as represented in e.g. the climatology (Medar, 2002, henceforth MEDATLAS), is small and that the effect can be neglected.

In Fig. 2 the differences between modeled and observed SSTs are shown. With a few exceptions, the modeled open ocean winter (JFM) and summer (JAS) SSTs are close to observations with a typical error smaller than $1 \mathrm{~K}$. In the model, SST refers to the temperature of the uppermost layer, which has a thickness of $12 \mathrm{~m}$ plus sea level. For consistency, the observations have been linearly interpolated onto $6 \mathrm{~m}$ depth, the center of the uppermost model level.

In winter (JFM), the model shows a cold bias in the Levantine and Ionian Seas. SST errors in excess of $1 \mathrm{~K}$ are simulated in the northern edge of the Adriatic, southwest of Cyprus and in small regions south of Crete. In summer, the model produces too warm temperatures around the Strait of Gibraltar. This is probably an effect of the neglect of tides, which substantially would enhance vertical mixing and thus reduce the summer surface temperatures. Otherwise temperature errors larger than $1 \mathrm{~K}$ only occur near coasts and could 


\section{Temperature difference CTL - MEDATLAS}
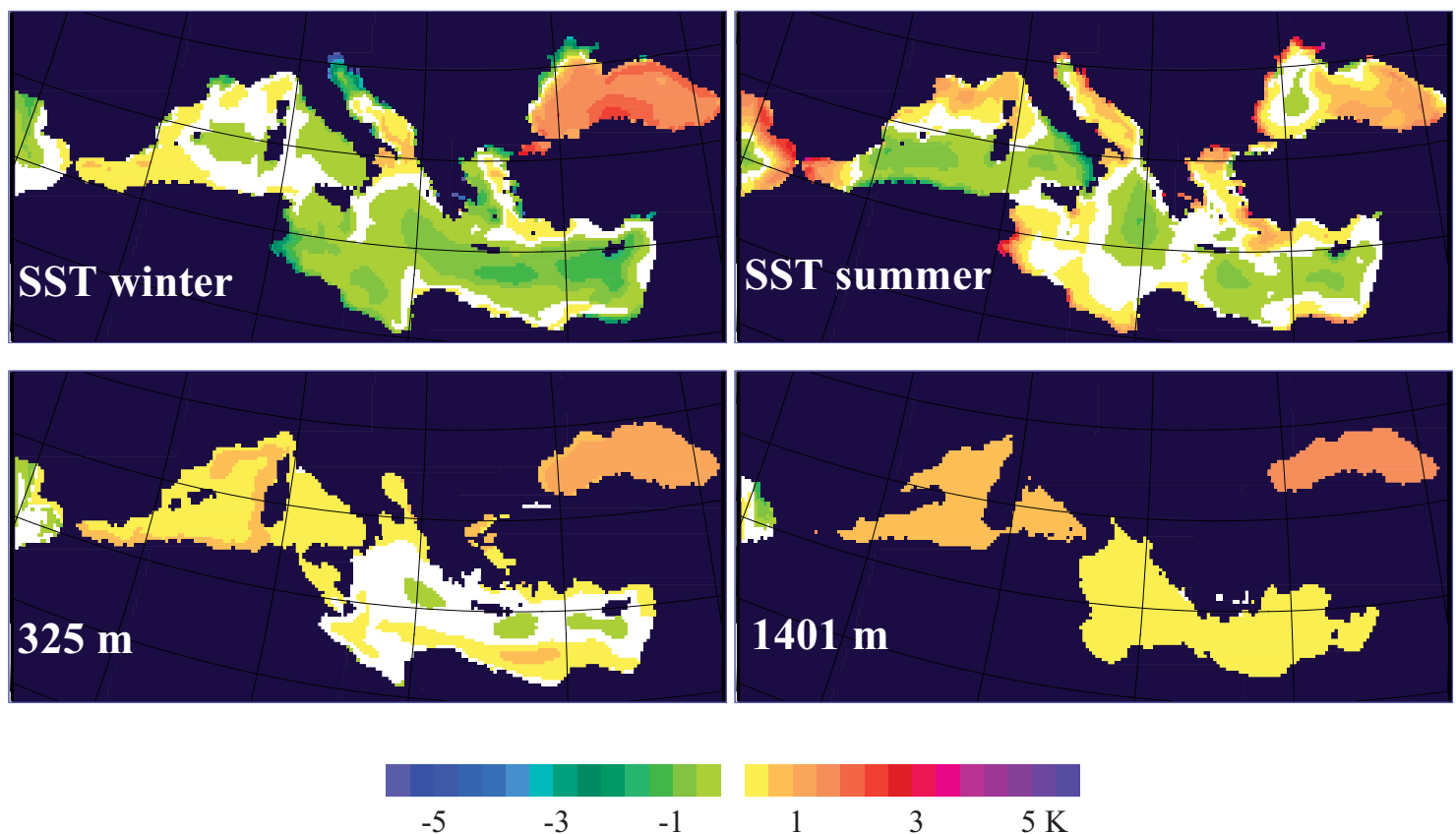

Fig. 2. Difference between simulated (CTL) and climatological (MEDATLAS) potential temperatures in K. Winter (JFM) and summer (JAS) SST and annual mean temperatures at $325 \mathrm{~m}$ and $1401 \mathrm{~m}$ depth. Contour interval is $0.4 \mathrm{~K}$. White indicates deviations smaller than $0.2 \mathrm{~K}$.

\section{Salinity and convection depth}

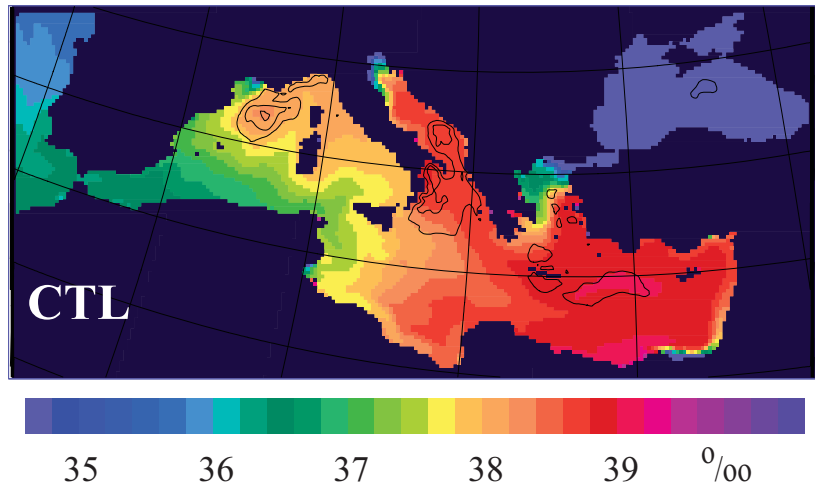

Fig. 3. The colours show the simulated annual mean surface salinity in CTL in \%o. Contour interval is $0.2 \%$ o. Isolines show the climatological maximum depth of the mixed layer. Contour interval is $250 \mathrm{~m}$.

be caused by small scale features in the atmospheric circulation, which are not resolved by the atmospheric forcing applied to the ocean model, like e.g. the strong positive bias in winter in the Marmara Sea.

At the depth of the intermediate water masses $(325 \mathrm{~m})$ the simulated western Mediterranean temperatures are ap- proximately $0.5 \mathrm{~K}$ warmer than climatology. In the eastern Mediterranean the pattern is characterized by slightly too cold water masses in the central Ionian and Levantine Seas, whereas coastal water masses are generally too warm (see Fig. 2). The simulated deep water masses (at $1401 \mathrm{~m}$ ) are generally too warm: $0.8 \mathrm{~K}$ in the western Mediterranean, $0.4 \mathrm{~K}$ in the eastern basin (see Fig. 2).

The simulated surface salinity as well as the deviations from the MEDATLAS climatology are displayed in Figs. 3 and 4. Whereas the calculation of surface heat fluxes using bulk formulas with modeled SSTs as ocean input implies a damping feedback on the modeled SSTs towards the imposed original climatology, there does not exist a similar feedback for surface salinity. Thus salinity tends to accumulate all errors in the hydrological forcing and in the circulation. The general structure of the simulated surface salinity is quite realistic. The model simulates the structure of relative fresh water entering the Mediterranean along the Algerian coast and saltier water masses in the Balearic Sea. The structure in the eastern Mediterranean is characterized by the inflow of low salinity water from the west and recirculation of saltier water at the coasts. The outflow from the Bosphorus is spreading along the coast of Greece. The Adriatic is characterized by inflow of salty surface and subsurface waters from the Ionian in the east. In the west, the plume of the Po is spreading southward along the Italian coast. 
Salinity difference CTL - MEDATLAS
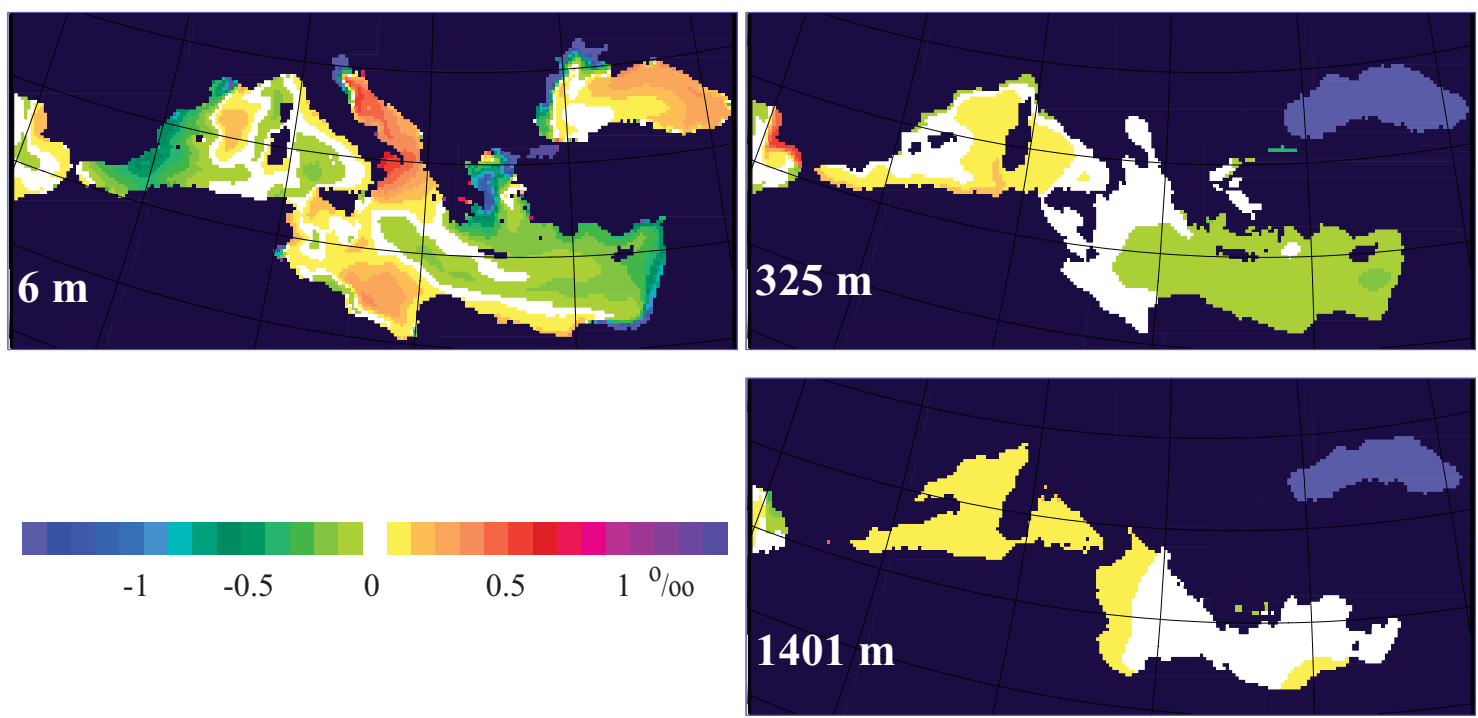

Fig. 4. Difference between simulated (CTL) and climatological annual mean salinity (MEDATLAS) for the surface, $325 \mathrm{~m}$ and $1401 \mathrm{~m}$. Contour interval is $0.1 \%$. White indicates deviations smaller than $0.05 \%$ o.

The model somewhat overestimates the salinity in the northern and southern Ionian and underestimates the salinity in the Levantine (see Fig. 4). The overestimation of the Nile runoff is responsible for the strong negative anomalies along the eastern margin of the Levantine. Part of this model data discrepancy, however, is likely to be an artifact due to insufficient representation of the plume of the Nile in the MEDATLAS climatology, both due to the reduction in Nile discharge as a consequence of the Aswan dam and due to too much spatial smoothing in the data processing. Whereas the northernmost part of the Adriatic is more than $1 \%$ o too fresh, the central and southern parts are too salty, indicating an overestimation of the inflow of salty water from the Ionian. The too fresh water in the northern and western Aegean are connected with the outflow from the Black Sea.

At depth the model errors are much smaller than at the surface (see Fig. 4). A typical error at $325 \mathrm{~m}$ depth is $-0.07 \%$ in the eastern basin and $0.05 \% \mathrm{o}$ in the western basin. At $1401 \mathrm{~m}$ depth, the errors are approximately $0.13 \%$ in the western basin and $0.04 \%$ in the eastern basin. It should be stressed that the water mass properties discussed here are entirely model generated and not spurious remainders of the initial conditions.

Sites of convective deep and intermediate water formation are indicated in Fig. 3. The mixed layer depth is a diagnostic quantity of the model. It is calculated as the depth, where the potential density is $0.05 \mathrm{~kg} \mathrm{~m}^{-3}$ larger than at the surface. In the western basin, the deep water is formed mainly in the Gulf of Lion. Some convection also takes place in the Ligurian Sea. In the eastern basin, deep water is formed in the Adriatic, and in the northwestern part of the Ionian. This pat- tern of deep winter mixed layer depths is largely consistent with the mixed layer climatology of D'Ortenzio et al. (2005). The mean mixed layer depth is a time average over potentially very different years. In some of the years the deep convection in the southern Adriatic actually reaches the model bottom, but it does not in other years. The interpretation of deep or intermediate water formation has throughout this paper always been crosschecked with radioactive age tracers, which were included in the simulations.

By far the highest densities in the bottom layer are simulated in the northern Adriatic. Here the water flows southward along the western margin, filling the deep southern Adriatic. Together with water formed by open ocean convection in the southern Adriatic, this forms the deep overflow water entering the Ionian through the Strait of Otranto. The entrainment of less dense ambient water on the way to the south is quite large, which is a typical feature of insufficient resolution of plume flow in z-coordinate models. As a consequence of this entrainment the convection in the northwestern Ionian is overestimated.

Levantine intermediate water (LIW) is formed around Crete and between Crete and Cyprus, where the high salinities allow sufficient high densities. The pattern is - with the exception of the overestimation of the convection in the northwestern Ionian - quite realistic (Pickard and Emery, 1990).

In winter the Black Sea SST is approximately $1.5 \mathrm{~K}$ too warm, in summer the temperature error is smaller (approx. $0.5 \mathrm{~K})$. The water at depth is more than $1 \mathrm{~K}$ too warm. Whereas the surface water in the interior is slightly too salty, the deep water is much too fresh. However, the model drift 
Table 1. Hydrological budget of the Mediterranean. Numbers are given in $1000 \mathrm{~m}^{3} \mathrm{~s}^{-1}$ unless specified explicitely on top of the column. Numbers in $\mathrm{myr}^{-1}$ are basin averaged fluxes.

\begin{tabular}{|c|c|c|c|c|c|c|}
\hline & \multicolumn{2}{|c|}{$\begin{array}{c}\text { CTL } \\
\text { Mediterranean } \\
\text { myr }^{-1}\end{array}$} & \multirow{2}{*}{$\begin{array}{r}\text { CTL } \\
\text { Black Sea } \\
7.9\end{array}$} & \multirow{2}{*}{$\begin{array}{l}\text { CTL } \\
\text { total } \\
39.9\end{array}$} & \multicolumn{2}{|c|}{$\begin{array}{c}\text { LGM } \\
\text { Mediterranean } \\
\text { myr }^{-1}\end{array}$} \\
\hline precipitation & 32.1 & 0.39 & & & 30.4 & 0.43 \\
\hline evapaporation & -97.3 & -1.19 & -12.7 & -110.0 & -77.8 & 1.10 \\
\hline river runoff & 11.3 & 0.14 & 11.7 & 23.0 & 19.3 & 0.27 \\
\hline net flux & -53.9 & -0.66 & 6.9 & -47.0 & -28.2 & -0.40 \\
\hline
\end{tabular}

in the Black Sea towards saltier conditions is still substantial. Nevertheless, the strong overestimation of the width of the Bosphorus due to the model resolution is a limiting factor for the ability of the model to realistically simulate the climate of the Black Sea.

The model simulates a deep outflow of $0.81 \mathrm{~Sv}$ through the Strait of Gibraltar. The inflow of Atlantic water is with $0.86 \mathrm{~Sv}$ slightly higher due to the need to compensate for the net evaporation of $47000 \mathrm{~m}^{3} \mathrm{~s}^{-1}$. Bryden et al. (1994) estimated the time-average outflow of Mediterranean water through the Strait of Gibraltar from hydrographic measurements to be $0.68 \mathrm{~Sv}$. Baschek et al. (2001) from current meter moorings $0.81 \mathrm{~Sv}$. Older estimates are somewhat higher, Lacombe and Richez (1982) estimated this to be $1.15 \mathrm{~Sv}$, Bethoux (1979) even 1.6 Sv. Thus the model outflow is quite realistic and consistent with actual estimates.

The near-surface circulation in run CTL shows in the western basin a strong Atlantic inflow in the southern part exiting through the Strait of Sicily into the eastern basin (see Fig. 5). The Gulf of Lion is characterized by a strong cyclonic circulation associated with the deep water formation cell. In the Tyrrhenian Sea the water flows first eastward north of Sicily and then follows the Italian coast northward. In the eastern basin, the continuation of the Atlantic inflow propagates as a mid-ocean jet into the Levantine basin. Together with a strong westward current along the Turkish coast, this forms the Rhodes gyre associated with the formation of Levantine intermediate water. Jointly with outflow water from the Black Sea, this feeds the northward surface flow along the Greek and Albanian coasts. The Adriatic shows a clear cyclonic circulation, which is mostly a summer and fall phenomenon. The surface circulation in the Black Sea is cyclonic as well. The general circulation pattern agrees quite well with the findings presented by Pinardi and Massetti (2000).

The hydrological cycle of the model (see Table 1) is a combination of prescribed quantities (precipitation and river runoff), which were derived from the ECHAM5 T106 simulations, and interactively calculated evaporation, which depends on the model SST. In the control simulation, the Mediterranean gains $32100 \mathrm{~m}^{3} \mathrm{~s}^{-1}$ from precipitation, $11300 \mathrm{~m}^{3} \mathrm{~s}^{-1}$ from river runoff and loses $97300 \mathrm{~m}^{3} \mathrm{~s}^{-1}$ by

\section{Currents 27m}

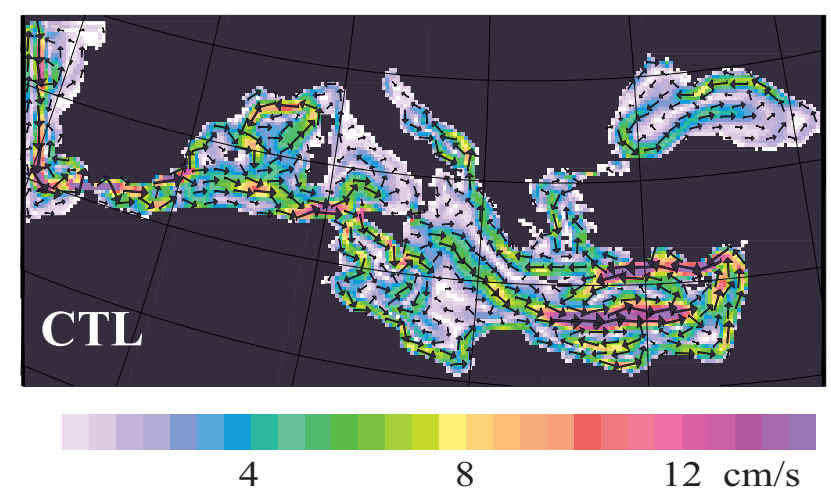

Fig. 5. Currents at $27 \mathrm{~m}$ depth for CTL. Colours indicate the flow speed in $\mathrm{cm} \mathrm{s}^{-1}$, vectors both direction and speed. Only a subset of vectors has been plotted.

evaporation. The Black Sea and the Marmara Sea have a net surplus of freshwater of $6900 \mathrm{~m}^{3} \mathrm{~s}^{-1}$, which is dominated by river input. Thus the net freshwater loss east of the Strait of Gibraltar is $47000 \mathrm{~m}^{3} \mathrm{~s}^{-1}$, which corresponds to the net inflow from the Atlantic.

The basin mean (Mediterranean only) of the prescribed precipitation is $0.39 \mathrm{~m} / \mathrm{yr}$. This agrees quite well with the results from NCEP and ECMWF reanalyses ( 0.43 and $0.33 \mathrm{~m} / \mathrm{yr}$ for the years 1979 to 1993 according to Mariotti et al. (2002). The classical estimates from observation are somewhat higher than these value: 0.55 (Jaeger, 1976), $0.7 \mathrm{~m} / \mathrm{yr}$ (Legates and Willmott, 1990) and $0.48 \mathrm{~m} / \mathrm{yr}$ (CMAP, Xie and Arkin, 1998). The basin mean calculated evaporation is $1.19 \mathrm{~m} / \mathrm{yr}$. The mean values (1979-1993) from the reanalysis of NCEP and ECMWF are 0.93 and $1.11 \mathrm{~m} / \mathrm{yr}$. Estimates from observations are slightly higher with 1.21 (Jaeger, 1976), 1.36-1.54 (Bethoux and Genitili, 1999) and $1.18 \mathrm{~m} / \mathrm{yr}$ (Mariotti et al., 2002). Both precipitation and evaporation are close to estimates from observations and reanalysis data.

The total freshwater budget of the Black Sea is quite realistic and close to observations (e.g. Tolmazin, 1985). The range of river discharge rates for the Mediterranean given in 
Anomalies LGM-CTL

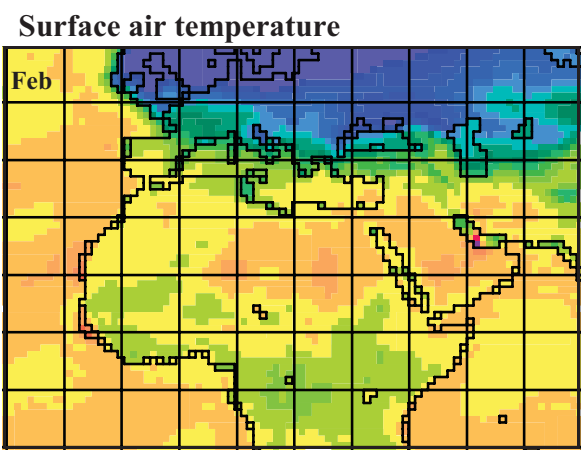

Precipitation - Evaporation
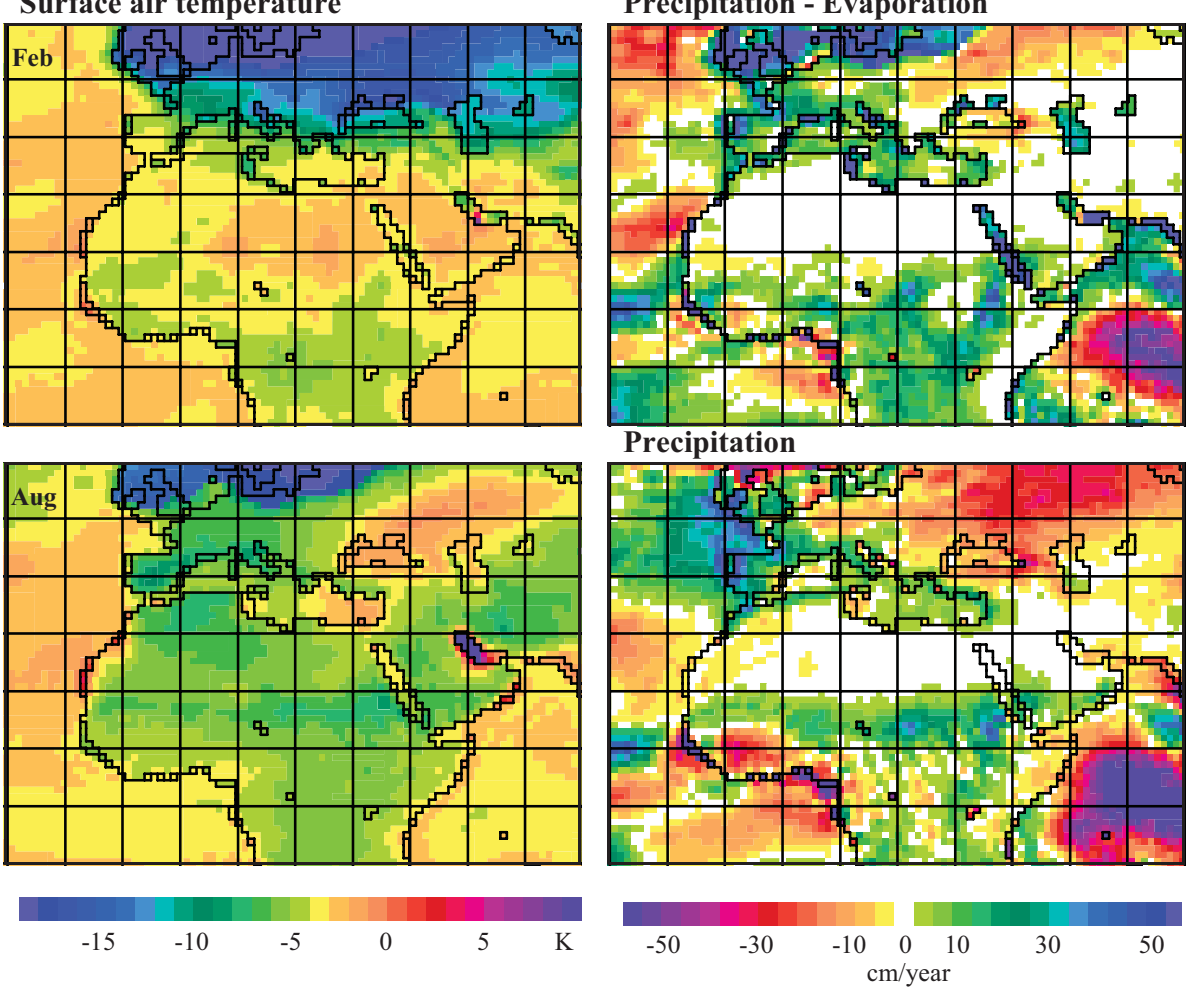

Fig. 6. Difference between LGM and present day simulations with the stand-alone ECHAM5 T106 atmospheric model. Left: Difference in surface air temperature between LGM and present day in K for February (top) and August (bottom). Right: difference in annual mean precipitation minus evaporation (top) and precipitation (bottom). Contour interval is $4 \mathrm{~cm} / \mathrm{yr}$, white colour indicates changes less than $2 \mathrm{~cm} / \mathrm{yr}$. Both present day and LGM coastlines are shown.

the review paper by Ludwig et al. (2009) lies with 12700 to $14300 \mathrm{~m}^{3} \mathrm{~s}^{-1}$ close to the model value of $11300 \mathrm{~m}^{3} \mathrm{~s}^{-1}$. The corresponding value for the Black Sea are 11100 to $12700 \mathrm{~m}^{3} \mathrm{~s}^{-1}$ compared to $11700 \mathrm{~m}^{3} \mathrm{~s}^{-1}$ from the model.

Bryden et al. (1994) estimate the total freshwater loss of the Mediterranean from hydrographic measurements in the Strait of Gibraltar to be $0.52 \mathrm{~m} / \mathrm{yr}$. The total freshwater loss of the model east of Gibraltar is $47000 \mathrm{~m}^{3} \mathrm{~s}^{-1}$ corresponding to $0.57 \mathrm{~m} / \mathrm{yr}$ if related to the area of the Mediterranean. Earlier estimates from hydrographic data yield - consistent with the higher outflow rates and similar salinity differences between inflowing and outflowing water at Gibraltar - higher estimates of the net evaporation of the Mediterranean Sea: e.g. $0.75 \mathrm{~m} / \mathrm{yr}$ (Lacombe and Richez, 1982) and $0.95 \mathrm{~m} / \mathrm{yr}$ (Bethoux, 1979). Estimates involving precipitation and evaporation from reanalyses tend to be somewhat lower (between 0.37 and $0.52 \mathrm{~m} / \mathrm{yr}$, see e.g. Mariotti et al. (2002). In general, the hydrological cycle of this model is well within the estimates from both observations and from reanalysis data.

\section{Boundary conditions LGM}

For the LGM simulation, the topography was modified adding the anomalies from the ICE-5G reconstructions (Peltier, 2004) between 21 and $0 \mathrm{kyr}$ B.P. to the standard topography. This resulted in reductions of the water depth between $127 \mathrm{~m}$ in the interior of the basin and $98 \mathrm{~m}$ in coastal areas (see Fig. 1 bottom). The sill depth at the Strait of Gibraltar has been reduced from 256 to $156 \mathrm{~m}$. Temperature and salinity, which are used for restoring at the western margin of the Atlantic box, are modified by adding the difference between LGM and CTL simulations with the coarse resolution ESM. The Bosphorus is closed and thus the Black Sea no longer part of the model. Aksu et al. (1999) reports for the LGM a lake level of the Black Sea $150 \mathrm{~m}$ lower than today. As this is lower than the sea level in the Mediterranean, river runoff from the Black Sea is not taken into account for LGM.

The climate of the LGM simulation over Europe is discussed in Arpe et al. (2011). Here only those aspects important for the Mediterranean ocean climate are discussed. The near-surface air temperatures are much colder than in the control simulation (see Fig. 6). In February, the temperature anomaly is characterized by a strong north-south gradient 


\section{Surface temperature LGM}
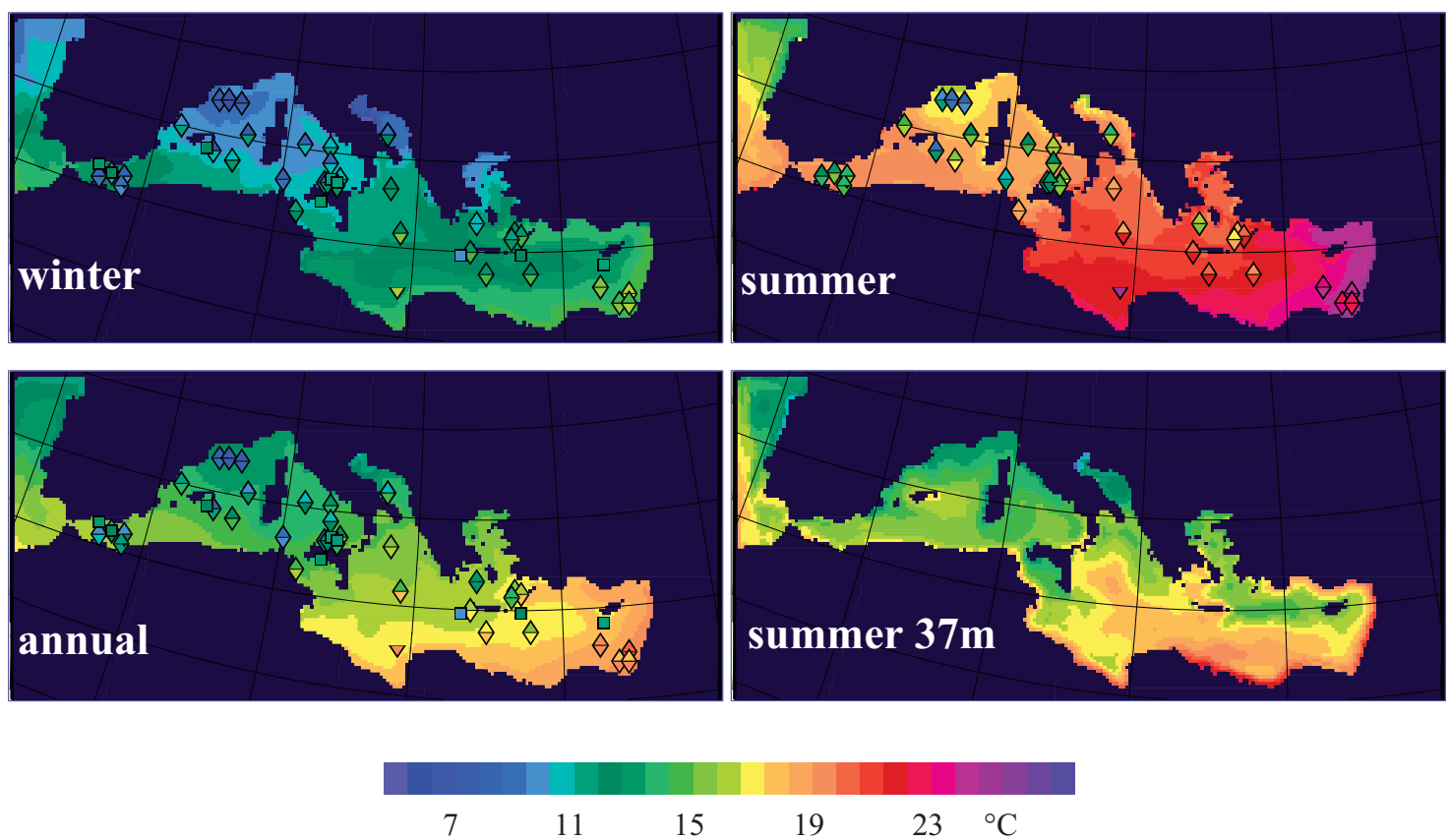

Fig. 7. Simulated temperature in the LGM simulation in ${ }^{\circ} \mathrm{C}$. Winter (JFM) SST, annual mean SST, summer (JAS) SST and summer temperature at $37 \mathrm{~m}$ depth. Downward triangles represent ANN reconstructions, upward looking triangles represent RAM reconstructions (Hayes et al., 2005). Alkenone derived temperature estimates (Lee, 2004) are represented by squares. Extending the suggestion by Emeis et al. (2000), alkenone temperature estimates have also been plotted for winter.

with a cooling exceeding $10 \mathrm{~K}$ over the Alps and on the Balkan and a cooling of less than $3 \mathrm{~K}$ in the northeastern Sahara and on the Arabian peninsula. The cooling is particularly strong in that part of the northern Adriatic which is converted to land due to the lower sea level. The changes in albedo and the strongly reduced heat capacity are responsible for this strong winter cooling signal.

In August, the simulated near-surface air temperature anomaly shows a clear east-west gradient. In central Spain, the simulated summer cooling reaches $9 \mathrm{~K}$, in the northern half of Italy, it exceeds $7 \mathrm{~K}$, whereas the cooling in the land areas around the eastern Levantine is typically $5 \mathrm{~K}$. Over the Mediterranean, the simulated cooling of air temperature anomalies is reduced compared to the land signal, but the longitudinal gradient is similar.

Temperatures over the Mediterranean land areas have been reconstructed from pollen data. Wu et al. (2007, their Fig. 8) estimated the temperature of the coldest month at LGM to be between 6 and $19 \mathrm{~K}$ colder than present, and the temperature of the warmest month to be between 2 and $11 \mathrm{~K}$ colder.

The anomalies of precipitation minus evaporation (from the atmospheric model) over the Mediterranean are in general positive (see Fig. 6). The strongest local changes occur in those regions which are converted from ocean to land. The changes in precipitation are positive for the eastern Mediter- ranean and the Tyrrhenian Sea, whereas they are rather small in the western basin (cf. Fig. 6). The enhanced precipitation in the eastern Levantine is consistent with higher lake levels of the Dead Sea (Stein et al., 2009). Integrated over the basin, precipitation is slightly reduced, which reflects mostly the effect of the reduced area (s. Table 1). Evaporation is reduced due to the lower temperatures. Thus the positive signal in precipitation minus evaporation is much larger than the precipitation signal. Precipitation is enhanced over France and Spain. The precipitation increase over France is strongest in summer.

The simulated precipitation is enhanced over the source regions of the Nile. The consequence is a strongly enhanced discharge from the Nile. It almost doubles compared to the control state. Reeder et al. (2002) estimated from the lack of turbidites that Nile discharge is strongly reduced during the LGM. Almogi-Labin et al. (2009) report a considerable Nile discharge during the LGM from sediment cores in the Levantine. The simulated runoff from Spain, France, the Alps, Italy and Croatia is strongly enhanced as well due to enhanced precipitation. As a consequence, the total river runoff into the Mediterranean is increased by $70 \%$ compared to present day (see Table 1). The basin integrated evaporation (calculated in the ocean model) is reduced by $20 \%$. The reduced evaporation is the major contribution to the reduced freshwater loss 


\section{Temperature difference $6 \mathrm{~m}-37 \mathrm{~m}$}
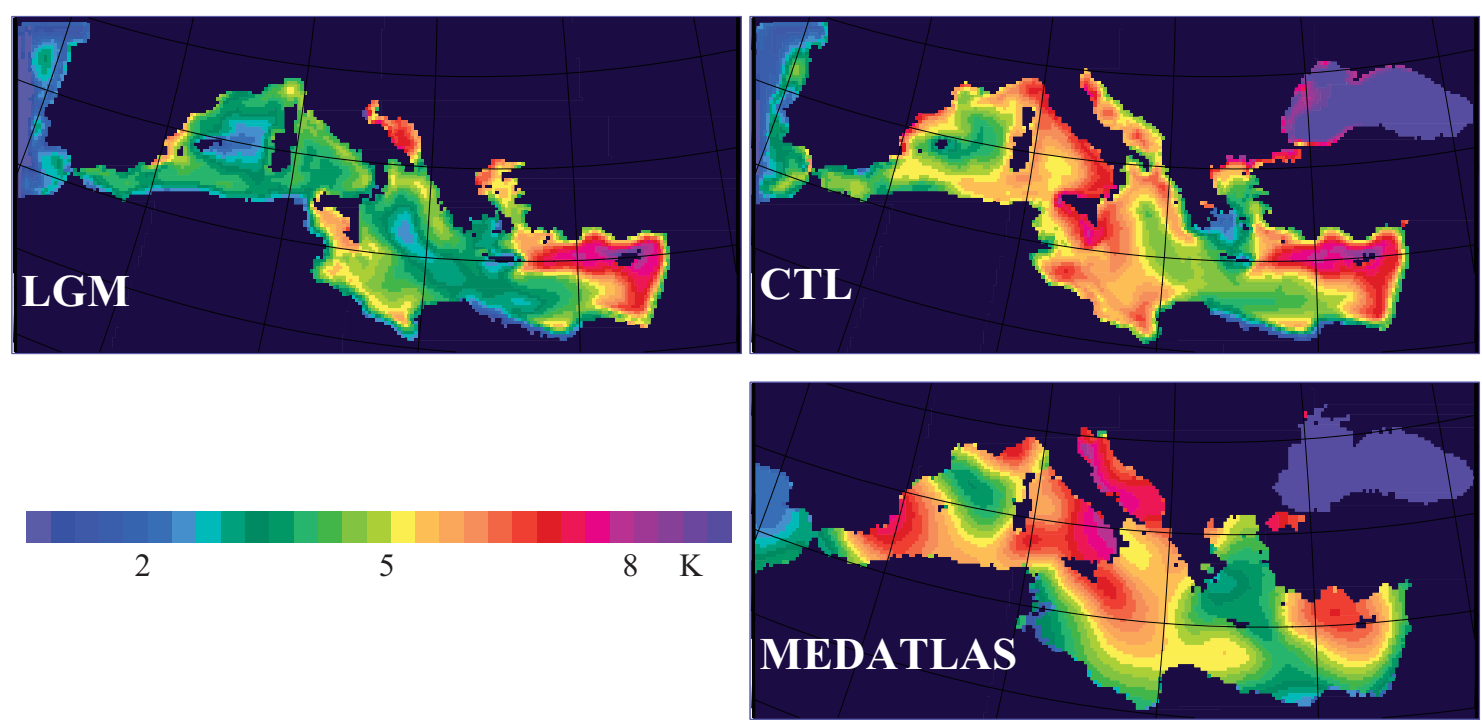

Fig. 8. Differences between summer (JAS) temperatures at 6 and $37 \mathrm{~m}$ in K. LGM, CTL and observations (MEDATLAS).

of the Mediterranean (28 200 compared to $47000 \mathrm{~m}^{3} \mathrm{~s}^{-1}$ for CTL). The enhanced river runoff compensates for the missing outflow from the Black Sea.

The simulated precipitation changes in tropical eastern Africa vary considerably between the different models. The high resolution atmosphere-only simulation from Kim et al. (2008) seems to show higher precipitation. On the other hand, Braconnot et al. (2007) report reduced precipitation as the mean outcome from several coupled atmosphere-ocean GCMs. Results from several high resolution simulations for Europe with different models did not show a consistent picture for the changes in precipitation in the Mediterranean region (Jost et al., 2005, their Fig. 5).

$\mathrm{Wu}$ et al. (2007) estimated reduced precipitation around the Mediterranean and in tropical east Africa from pollen data using an inverse vegetation model. Farrera et al. (1999) estimated from various proxy data reduced precipitation in tropical east Africa, but increased precipitation minus evaporation. Lake levels around the Mediterranean were higher, although only few data are available (Kohfeld and Harrison, 2000). In tropical east Africa, lake level data are inconclusive, about as many data hint to wetter conditions as to dryer conditions.

\section{Results LGM}

The baseline LGM simulation has been integrated for 2099 years.

\subsection{Temperature}

The simulated SSTs are shown in Fig. 7 together with reconstructions derived from marine sediment cores. Temperatures have been estimated from assemblages of planktonic foraminifera with two different methods (Hayes et al., 2005): The revised analog method (RAM, Waelbroeck et al., 1998) and the artificial neural network technique (ANN, Malmgren et al., 2001). For annual mean temperatures, additional estimates derived from alkenones have been used (Lee, 2004, and references therein).

Model and reconstructions agree on the general SST pattern for winter. The coldest temperatures occur in the Gulf of Lion and the Adriatic. The ANN estimates are somewhat warmer than the RAM estimates. In general, the model agrees reasonably well with both reconstructions. The model is too warm in the Alboran Sea, which can be explained by the combined effect of the lack of tidal mixing in the Strait of Gibraltar and the forcing. The ESM simulation showed only a moderate cooling in the Gulf of Cadiz in contrast to reconstructions. Thus the cooling between LGM and present of the inflowing Atlantic water is underestimated, which results in an overestimation of the surface temperatures in the Alboran Sea.

The temperature pattern in summer is quite similar. SSTs are cold in the north and warm in the southeastern Levantine. In the eastern basin, the agreement between model and the ANN reconstruction is reasonable. The estimate based on the RAM method is somewhat colder than the ANN reconstruction. In the Adriatic and east of Greece, the simulated SSTs are several degrees too warm compared to the proxy estimates. In the entire western Mediterranean the simulated 


\section{Surface temperature anomaly}
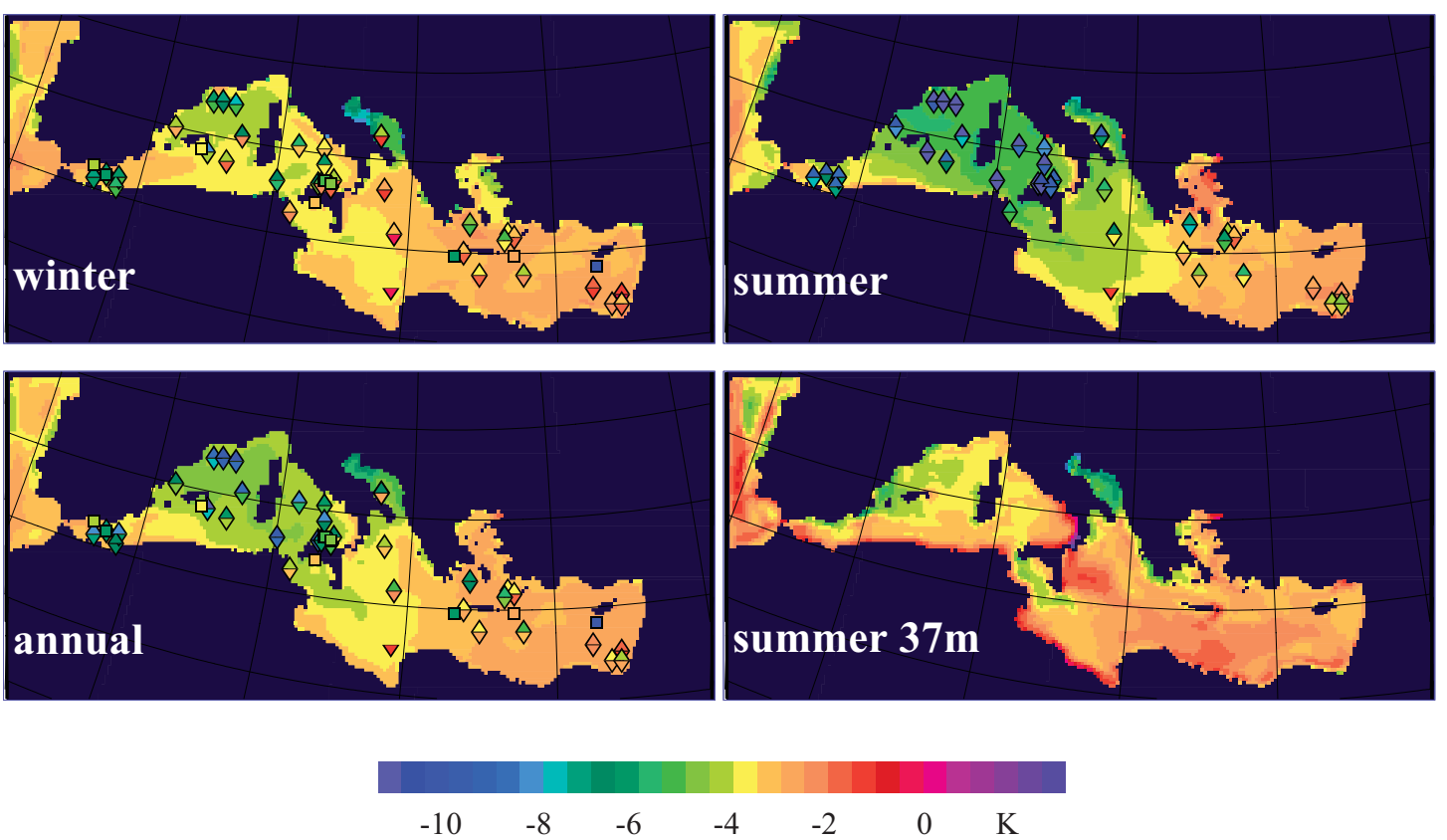

Fig. 9. Simuated temperature anomalies between LGM and CTL in K. Winter (JFM) SST, annual mean SST, summer (JAS) SST, and summer temperature anomalies at $37 \mathrm{~m}$ depth. Triangles represent anomalies between SST recontructions from assemblages of foraminifera (Hayes et al., 2005) and WOA98 temperatures at $10 \mathrm{~m}$ depth. Downward triangles represent reconstruction using the ANN method, upward looking triangles using the RAM method. Squares represent differences between alkenone derived temperature estimates for LGM and core top (Lee, 2004).

SSTs are substantially warmer than the proxy estimates. At this time of the year, however, there exists a strong vertical temperature gradient, with typical temperature differences between the surface and $37 \mathrm{~m}$ of 2 to $5 \mathrm{~K}$ (see Fig. 8). At $37 \mathrm{~m}$, the deviation between reconstructed and simulated temperatures in the western Mediterranean is much smaller than at the surface.

For the annual mean, the model reproduces the reconstructions in the eastern Mediterranean quite well, but is too warm in the western Mediterranean and the Alboran Sea due to the mismatch in summer. The annual mean temperatures have been reconstructed from alkenones (Lee, 2004, and references therein) as well. Whereas in the western Mediterranean these estimates agree quite well with the estimates from assemblages of foraminifera, the alkenone derived temperatures in the eastern Mediterranean are substantially colder than the other estimates. In this region, two of the three estimates from the core top in the data set supplied by Lee (2004) deviate by more than $4 \mathrm{~K}$ from present annual mean climatology. Emeis et al. (2000) have suggested that alkenones in the Mediterranean record winter and spring temperatures rather than annual mean temperatures. The alkenone temperatures in the eastern Mediterranean are as cold or even colder than the closest estimates for winter temperatures from Hayes et al. (2005) (see Fig. 7).
The anomalies between LGM and CTL are shown in Fig. 9. As for the reconstructions from assemblages of foraminifera no equivalent estimates of present surface temperatures are available, the data have been compared to observed hydrographic climatology. Following Hayes et al. (2005) the WOA (1998, henceforth WOA98) climatology is used. A comparison with temperature estimates derived with the same method from core top assemblages of foraminifera would clearly have been preferable, but these data are not available. Thus, this inconsistency introduces an additional source of error for the reconstructed temperature anomalies.

The simulated cooling in winter (Fig. 9) is typically $2.5 \mathrm{~K}$ in the Levantine and $4.5 \mathrm{~K}$ in the northwestern Mediterranean. The Adriatic experiences the strongest cooling with up to $8 \mathrm{~K}$. The anomalies of reconstructed winter temperatures relative to observed instrumental data show a quite similar pattern with a weak cooling in the Levantine and maximal cooling (more than $6 \mathrm{~K}$ ) of the northwestern Mediterranean. The model underestimates the cooling in the inflowing Atlantic water, which is a consequence of the forcing from the global ESM. In the reconstructions, the winter cooling in the Adriatic is rather small, clearly not consistent with the strong cooling in the model. However, the two reconstruction methods show large deviations at this location. The ANN proxy estimates yield systematically smaller climate 
changes than the RAM estimates. Temperature differences between the two estimates of $2 \mathrm{~K}$ are not infrequent.

The simulated change in summer SST (Fig. 9) is dominated by the strong east-west gradient with a weak cooling ( 2 to $3 \mathrm{~K}$ ) in the Levantine and more than $6 \mathrm{~K}$ in the Gulf of Lion and the Adriatic. The general pattern of temperature change derived from the proxy estimates is quite similar, but the model underestimates especially the cooling in the northwestern Mediterranean, which amounts to values of $10 \mathrm{~K}$ or more in the proxy reconstructions. There is, however, a substantial depth dependence of the simulated temperature anomaly, as is revealed in a comparison of the summer surface temperature signal with the signal at $37 \mathrm{~m}$ depth.

The simulated annual mean SST difference between LGM and CTL (Fig. 9) shows the same gradient between the Levantine and the Gulf of Lion as the summer and winter signals. With respect to reconstructions, the model underestimates this gradient. In general, the model is closer to the ANN reconstructions. The alkenone derived temperature changes (relative to the core top data) suggest slightly less cooling in the western Mediterranean than the Hayes et al. estimates. In the eastern Mediterranean the cooling derived from alkenones ranges from 2.7 to $10.1 \mathrm{~K}$. This suggests that these data might not only record changes in annual mean temperature, but potentially also changes in season and/or depth of the plankton production.

The reconstructions from assemblages of foraminifera have formally been performed for temperatures at $10 \mathrm{~m}$ depth, but the foraminifera are living over a wider depth range. Thus, it might be more appropriate to compare the estimates with the temperatures integrated over a depth range corresponding to the habitat of the foraminifera. Doing this in a proper way would require to repeat the estimation of the transfer function using depth integrated temperatures as input data. In winter this problem is not relevant as the vertical temperature gradient is small due to the deeper winter mixed layers.

An earlier estimate of LGM SSTs in the Mediterranean by Thiede (1978) agrees quite well with the general pattern of the simulated SST differences between LGM and present. Thiede reports the presence of a rather cold water mass protruding in a narrow tongue southward from the eastern Aegean as far south as $33^{\circ} \mathrm{N}$, which is absent in the reconstruction from Hayes et al. (2005) and in the simulations. Bigg (1994) reported a change in simulated annual mean SST between his LGM and control simulations with a clear east west gradient with more than $4 \mathrm{~K}$ cooling in the Alboran Sea and less than $1 \mathrm{~K}$ at the Libyan coast.

In the simulation of the LGM in the atmosphere model, the orographic forcing exerted by the Fennoscandian ice sheet causes a southward displacement of the belt of westerly winds over Europe (see Fig. 10). This disturbance is essentially barotropic. In summer, this leads to enhanced advection of cold and moist air of Atlantic origin over the gap between the Alps and the Pyrenees onto the northwest- ern Mediterranean. This results in enhanced cloud cover and precipitation (see Fig. 6) over Spain, southern France and northern Italy. The increased soil moisture amplifies the evaporative heat loss and thus the surface cooling. The shortwave radiation reaching the surface is reduced here and over the western Mediterranean due to the enhanced cloud cover with a maximal effect in the Gulf of Lion (approximately $12 \mathrm{~W} / \mathrm{m}^{2}$ less absorbed short wave radiation than in $\mathrm{CTL}$ ). The enhanced winds over the northwestern Mediterranean (see Fig. 10) amplify the advection of cold air onto the Gulf of Lion, leading to a cooling of the ocean surface by sensible heat flux. The stronger near-surface winds (Fig. 10 right) enhance turbulent vertical mixing, thus distributing the summer warming over a wider depth range in run LGM than in CTL (see Fig. 8). The wind induced mixing is increased in JJA by almost 50\% in the northwestern Mediterranean, in the Tyrrhenian Sea by even $67 \%$. The result is a rather strong surface cooling in run LGM in the northwestern Mediterranean compared to the rest of the Mediterranean. At $37 \mathrm{~m}$ depth this anomalous cooling pattern has essentially vanished, creating a cooling pattern which is very similar to the winter pattern. The ability of the model to reproduce this pattern realistically for present day becomes obvious by comparison of CTL with the MEDATLAS climatology.

The enhanced inflow of moist and cool Atlantic air into the Mediterranean was also suggested by Kuhlemann et al. (2008) from changes in reconstructed glacier equilibrium line altitude.

In the Alboran Sea the winds are weaker for the LGM summer than for present (see Fig. 10). The reduced wind induced mixing enhances the vertical temperature gradient (see Fig. 8). The simulated summer surface temperature anomalies are clearly warmer than the reconstructions. If the reconstructed temperatures contain a subsurface signal as well, this could explain part of the deviation between model and reconstructions (see Fig. 9).

At $1401 \mathrm{~m}$ depth the simulated cooling between LGM and CTL is approximately $3.1 \mathrm{~K}$ in the Ionian and the Levantine and $4.7 \mathrm{~K}$ in the western basin.

The basin averaged annual long-term mean heat loss from the Mediterranean (see Table 2) is almost unchanged. The reduced heat loss by evaporation is compensated by increased heat loss by sensible heat fluxes and longwave radiation. The reduction in downward longwave radiation is only partially compensated by the reduced upward longwave radiation.

\subsection{Salinity and circulation}

During the LGM the global mean salinity was approximately $1 \%$ o higher than today due to the lower global sea level. The salinity anomaly for the Atlantic, which was derived from simulations with the coarse resolution ESM, is close to this value. The simulated surface salinity anomaly in the Mediterranean is substantially higher than this (see Fig. 11). 

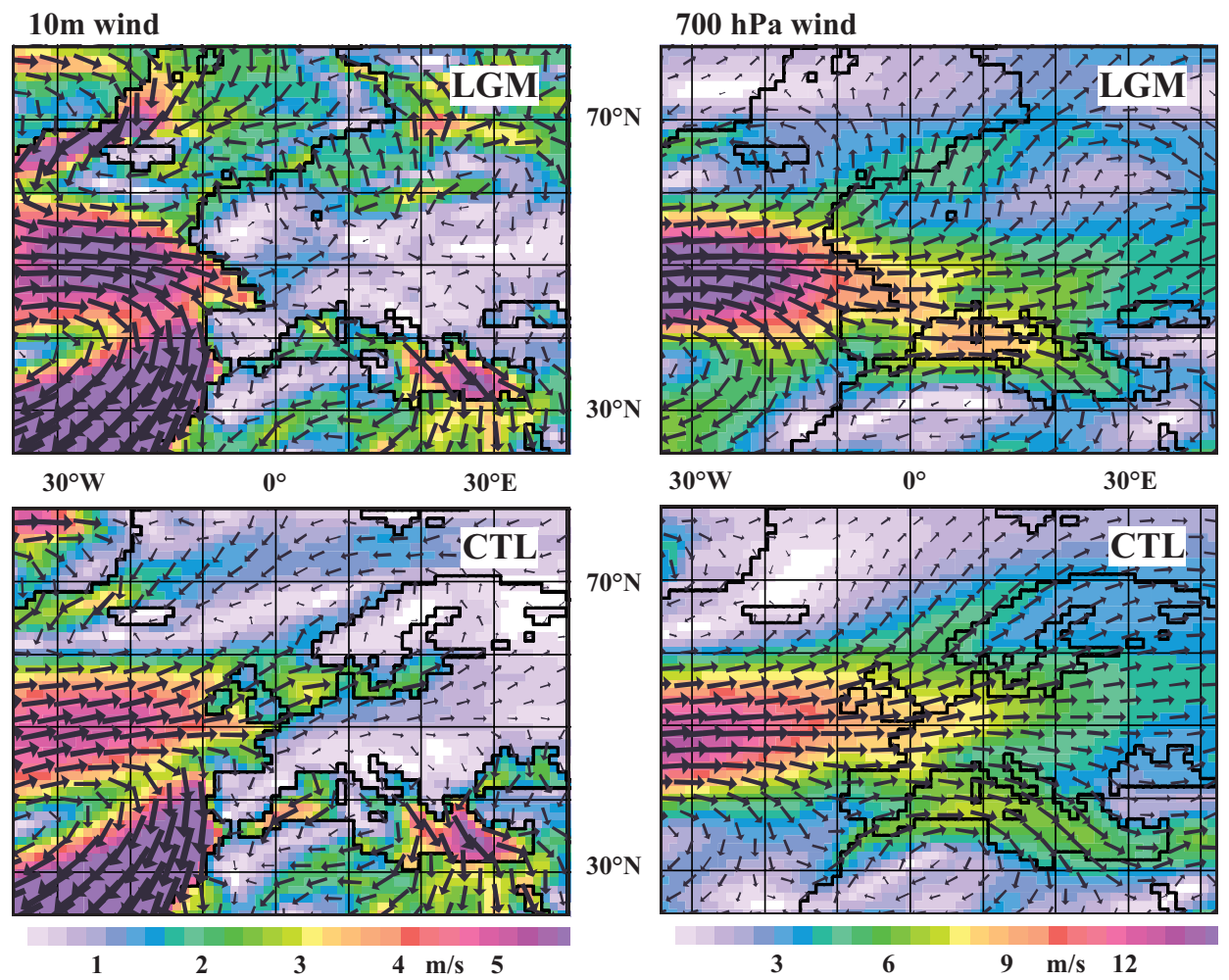

Fig. 10. Simulated summer (JAS) winds from the atmosphere model in $\mathrm{m} / \mathrm{s}$. The left panels show the near-surface winds, the right panels the wind at $700 \mathrm{hPa}$. The top panels show LGM, the bottom CTL. The data have been averaged over 20 model years.

The western Mediterranean is saltier by approximately $1.9 \%$ with higher values in the Tyrrhenian.

Surface salinity in the eastern Mediterranean increases by almost 2\% in the Levantine compared to CTL. East of Sicily, in the region with deep convection in LGM, the salinity anomaly is almost $3 \%$. The salinity here has typical values between 40.8 and $40.9 \%$, only about $0.1 \%$ o lower than the salinity maximum in the central Levantine. Regions with reduced salinities are the Adriatic and the plume of the Nile, which is extended in the LGM simulation due to the enhanced discharge from the Nile. In the Aegean, the increase of the salinity reaches maximal values, which is a consequence of the lacking outflow from the Black Sea and the associated tongue of relative fresh water in the northern and western Aegean (cf. Fig. 11). At a depth of $1401 \mathrm{~m}$ the salinity increase is $2.1 \%$ in the eastern basin and $1.7 \%$ in the western basin (not shown).

At first the increased salinity gradient between the Mediterranean and the Atlantic for the LGM seems to be counterintuitive in view of the fact that the net freshwater loss for the LGM is only $60 \%$ of the present value. However, the effect of the reduced exchange across the straits due to the lower sill depths, which leads to longer exposure times of the Mediterranean water masses to a net evaporation, is dominating (see below).
Table 2. Annual mean basin average heat fluxes for the Mediterranean in $\mathrm{W} / \mathrm{m}^{2}$.

\begin{tabular}{lrr}
\hline & CTL & LGM \\
\hline absorbed shortwave radiation & 168.2 & 169.3 \\
net longwave radiation & -68.1 & -73.1 \\
latent heat flux & -96.4 & -89.5 \\
sensible heat flux & -7.7 & -11.2 \\
total & 4.0 & 4.5 \\
\hline
\end{tabular}

Using strongly simplifying assumptions, Thunell and Williams (1989) estimated that the eastern Mediterranean was saltier by $2.7 \%$ compared to today, which is in close agreement with the model result. Their estimate of the salinity changes in the western Mediterranean is $1.2 \%$. Myers et al. (1998) estimated even higher values for the salinity increase in the Levantine and used them as forcing for their model simulations.

Bigg (1994) showed only small changes in salinity between his LGM and CTL simulations, but his simulation was much too short (21 years) for substantial salinity anomalies to develop and it is rather unlikely that a steady state was reached. The control simulation of Bigg (1994) revealed 


\section{Salinity and convection depth}

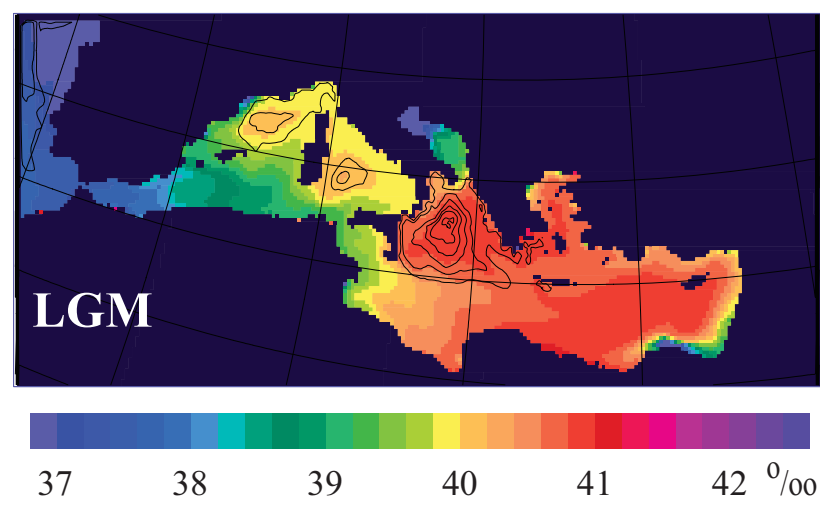

Salinity anomaly

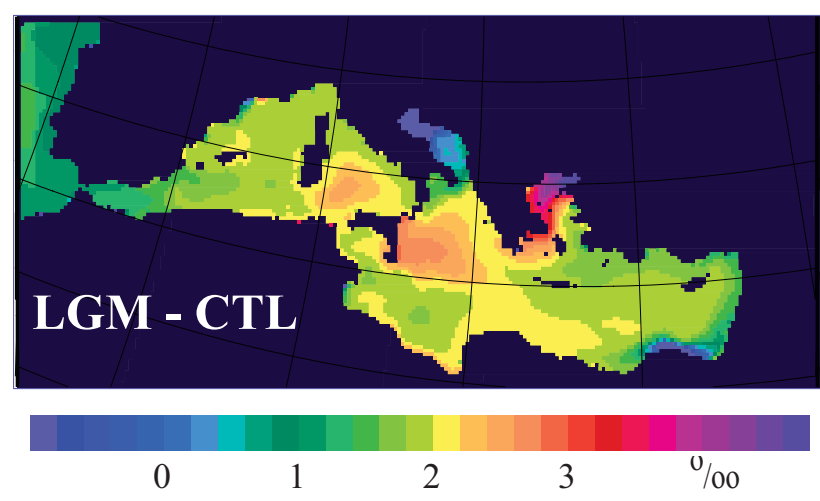

Fig. 11. Top: simulated annual mean surface salinity (colours, contour interval $0.2 \%$ ) and climatological maximum mixed layer depth (isolines, contour interval $250 \mathrm{~m}$ ) for LGM. For CTL see Fig. 3. Bottom: anomalies of surface salinity LGM minus CTL wth a contour interval of $0.2 \%$.

massive problems to reproduce the current Mediterranean ocean climate (e.g. an outflow from the Strait of Gibraltar of $0.1 \mathrm{~Sv}$, no deep water formation neither in the eastern nor in the western Mediterranean) and his simulations were much too short.

In the LGM simulation, the higher river runoff into the Adriatic has lead to an estuarine circulation pattern without deep convection (see Fig. 11 top). Deep water formation in the eastern basin is concentrated in the northern Ionian. The highest surface salinities (except for some almost isolated coastal points) are simulated in the central and southwestern Levantine. However, densities are not high enough to allow the formation of Levantine intermediate water, which can be attributed both to the reduced difference in salinity in the region of deep convection and to the relatively low winter cooling. The increased Nile discharge reduces the increase in surface salinities in the Levantine.

In the western Mediterranean, the Gulf of Lion is the main source of deep water in LGM. Here the local surface salinity reaches a maximum due to the mixing of surface waters with underlying warm and salty outflow water originating from the Strait of Sicily. By exposing this salty water to strong surface cooling, sufficiently dense water is formed. A similar process takes place in the western Tyrrhenian Sea resulting in formation of deep intermediate and occasionally even deep water.

Myers et al. (1998) obtained quite different changes in deep water formation. In their LGM simulation, the main site of deep water formation in the eastern basin was the Rhodes gyre region. For the LGM they prescribed the strongest salinity increase at the eastern margin of the Levantine. The anomaly pattern prescribed in their simulations is quite different from the pattern obtained in the simulations presented here, where the strongest increase in surface salinity occurs east of Sicily and in the Aegean (see Fig. 11). Thus, the completely different response of the circulation can be explained by their prescribed surface salinity anomaly. Their simulation shows an estuarine circulation in the Adriatic as well.

Various attempts have been made to test for the potential existence of multiple steady states of the Mediterranean circulation at LGM. All simulations seem to converge towards a similar state. The formulation of the boundary conditions with calculation of the heat fluxes from bulk formulas using atmospheric quantities and the actual model SST is a variant of the so called mixed boundary conditions (restoring of the SST towards a prescribed value and flux condition without restoring for salinity), which for the global ocean are known to overestimate the sensitivity of deep water formation cells towards perturbations (e.g. Mikolajewicz and Maier-Reimer, 1994). In the Mediterranean, however, this problem is probably less severe, as there are no strong oceanic heat transports involved, which could be modified and feed back onto the atmosphere. Additionally the Mediterranean is much smaller and surrounded by land, which also should make the formulation of the thermohaline boundary condition more appropriate for the current problem than for the problem of investigating the stability of the thermohaline circulation of the global ocean.

The deep outflow of Mediterranean water through the Strait of Gibraltar reaches only $0.40 \mathrm{~Sv}$, approximately $50 \%$ of the $0.81 \mathrm{~Sv}$ in CTL. The corresponding inflow is given by the necessity to balance the outflow and the net freshwater loss of the Mediterranean. The density difference between Mediterranean water and the adjacent Atlantic water increases from $2 \mathrm{~kg} \mathrm{~m}^{-3}$ to $3 \mathrm{~kg} \mathrm{~m}^{-3}$. In both cases the gradient has been estimated on the model level above the sill. The salinity difference increases from 2.5 to $3 \%$ o. In LGM the outflowing Mediterranean water is approx. $2 \mathrm{~K}$ colder than the water in the Gulf of Cadiz. This increases the density difference, whereas in CTL the temperature difference between Alboran Sea and Gulf of Cadiz is small and the density difference is almost entirely determined by salinity. The deep outflow from the Ionian Sea through the Strait of Sicily is reduced from $1.06 \mathrm{~Sv}$ to $0.63 \mathrm{~Sv}$. 
A similar reduction of the outflow of Mediterranean water through the Strait of Gibraltar has been found in the model study of Myers et al. (1998) with a somewhat stronger outflow. Bigg (1994) did not simulate substantial changes in Mediterranean outflow through the Strait of Gibraltar.

The reduction in transport through the Strait of Gibraltar by a factor of 2 is consistent with the reduction that would be caused by the lower sea level and the reduced cross-sectional area of the strait under the assumptions of hydraulic control in the Strait and overmixing in the Mediterranean (Bryden and Stommel, 1984; Rohling and Bryden, 1994). Alhammoud et al. (2010) found a similar dependence of the deep outflow from the sill depth in coarse resolution ocean GCM.

Using the analytical model of hydraulic control, Rohling and Bryden (1994) yield of reduction of the outflow to 53\% of the present value due to a change in sill depth corresponding to the one applied in our simulations. In a sensitivity experiment with present-day forcing but with the sill depths in the Straits of Sicily and Gibraltar reduced to LGM values (SILL, see Sect. 5.3), the Gibraltar outflow was reduced to $53 \%$ of CTL, which is identical to the results from the simple model. Taking into account the changes in net evaporation of the Mediterranean $E_{\mathrm{M}}$ to $60 \%$ of the CTL value $E_{\mathrm{M} 0}$ would lead to a further decrease. Rohling and Bryden (1994) suggested a dependence of the outflow of Mediterranean water $Q_{\mathrm{M}}$ on the net evaporation $E_{\mathrm{M}}$ relative to a reference state (indicated by the additional subscript 0 , the subcript $\mathrm{M}$ indicates Mediterranean properties)

$\frac{Q_{\mathrm{M}}}{Q_{\mathrm{M} 0}}=\sqrt[2]{\frac{E_{\mathrm{M}}}{E_{\mathrm{M} 0}}}$.

This would yield an additional reduction to $41 \%$ of the CTL value, thus overestimating the effect compared to the numerical model. Rohling (1999) used the dependence

$$
\frac{Q_{\mathrm{M}}}{Q_{\mathrm{M} 0}}=\sqrt[3]{\frac{E_{\mathrm{M}}}{E_{\mathrm{M} 0}}}
$$

based on results from the box model described by Matthiesen and Haines (2003). This relation yields a total reduction to $45 \%$ of the CTL value. Both formulas overestimate the reduction in outflow (to 41 and $45 \%$, respectively compared to $50 \%$ of the numerical model) as they do not take the temperature contribution to the density gradient into account, which enhances the outflow and thus compensates largely for the effect of the reduced net evaporation.

Following e.g. Bryden and Kinder (1991), the Mediterranean outflow through the strait of Gibraltar $Q_{\mathrm{M}}$ can for the case of hydraulic control and overmixing be expressed as

$Q_{\mathrm{M}}=\alpha \sqrt{\frac{\Delta \rho}{\rho_{\mathrm{M}}} g w^{2} h^{3}}$

where $\rho$ is the potential density, $w$ and $h$ are width and depth of the Strait of Gibraltar. $\alpha$ is a dimensionless factor. Bryden and Stommel (1984) estimate it to be 0.25 with the assumption that the interface between the two layers is at half depth. Farmer and Armi (1986) showed that the lower layer has to be thinner and give $\alpha=0.208$ for the maximum exchange solution.

If the density difference between lower and upper layer in the Strait of Gibraltar $\Delta \rho$ is entirely determined by the salinity difference, it can be expressed as $\beta \Delta S$, where $\beta$ is the derivative of the density with respect to salinity. For a steady state, the equations of salt and mass conservation yield

$\Delta S=\frac{E_{\mathrm{M}}}{Q_{\mathrm{M}}} S_{\mathrm{A}}$,

where the subscript A indicates Atlantic properties.

Combining Eqs. (3) and (4) yields

$Q_{\mathrm{M}}=\sqrt[3]{\alpha^{2} \frac{\beta S_{\mathrm{A}}}{\rho_{\mathrm{M}}} h^{3} w^{2} g E_{\mathrm{M}}}$.

Neglecting the changes in $\rho_{\mathrm{M}}$ leads immediately to the conclusion that the Mediterranean outflow $Q_{\mathrm{M}}$ is proportional to the depth of the strait and the third root of the net freshwater loss of the Mediterranean $E_{\mathrm{M}}$. The long-term mean exchange through the Strait of Gibraltar in the model is clearly subcritical, but the flow in the strait is quite variable due to the variable forcing.

The changes in the meridionally integrated zonal stream function (see Fig. 12) show the formation of eastern Mediterranean deep water around $15^{\circ} \mathrm{E}$ and its subsequent eastward spreading. The formation of deep water in the Gulf of Lion around $5^{\circ} \mathrm{E}$ is not captured well by this quantity, as much of the spreading occurs southward. Only the deep inflow into the Tyrrhenian Sea around $10^{\circ} \mathrm{E}$ as a negative cell and the deep outflow into the Alboran Sea are captured by this quantity. In LGM, the main overturning cell with intermediate water becomes shallower due to the shallower sills and the intensity is reduced in accordance with the overflows over the sills. In both simulations, salty surface waters are downwelled to the depth of intermediate water in the southwestern part of the Levantine, while upwelling is predominant in the northeastern part. There is some tendency of an intensification of the deep overturning cell in the western Mediterranean. Alhammoud et al. (2010) found a similar response in an idealized Mediterranean setup of on ocean GCM in response to a shallowing of the sill depth.

In LGM, the near-surface currents especially in the western basin intensify (see Fig. 13) due to enhanced wind forcing. Apart from a strong cyclonic gyre in the Tyrrhenian, the basic current structure is similar. The changes in the eastern basin are substantial. The cyclonic circulation in the Adriatic has vanished. The closure of the Bosphorus leads to strong changes in the surface circulation of the Aegean. The northern Ionian is characterized by a strong cyclonic gyre. The eastward flow along the coast of Egypt has substantially weakened. 


\section{Zonal overturning stream function [Sv]}
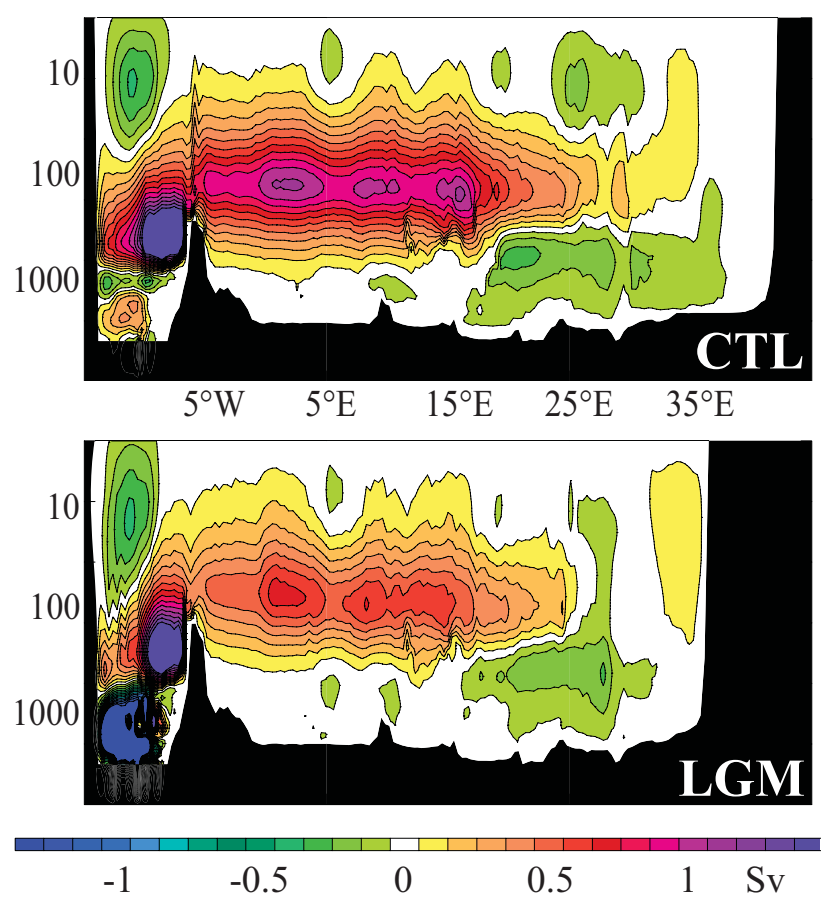

Fig. 12. Meridionally integrated zonal overturning stream function in Sv. Positive values indicate clockwise circulation. The $\mathrm{x}$-axis shows longitude, the $\mathrm{y}$-axis depth in $\mathrm{m}$ on a logarhithmic scale. The top panel shows CTL, the bottom panel LGM. Contour value is $0.1 \mathrm{~Sv}$, white indicates values smaller than $\pm 0.05 \mathrm{~Sv}$.

\subsection{Sensitivity experiments}

One of the main uncertainties in the LGM experiment is the hydrological forcing, especially the Nile discharge. In order to test the potential effect of inadequate hydrological forcing, two sensitivity experiments for the LGM were carried out. In experiment LGM-N2 the discharge of the Nile was doubled compared to LGM, in experiment LGM-N0 the Nile was completely eliminated. The annual mean changes in net freshwater flux of the Mediterranean resulting from this relative to LGM are $\pm 9700 \mathrm{~m}^{3} \mathrm{~s}^{-1}$. Both simulations were started in year 99 from the same state as LGM and integrated for 1500 additional years. Surface salinity and winter mixed layer depths from these experiments are shown in Fig. 14.

It is obvious from comparison of Figs. 11 top and 14 that the Nile discharge has a strong influence on the surface salinities in the eastern Mediterranean. A removal of the Nile increases the surface salinities in the eastern Mediterranean by approx. $0.7 \%$, a doubling reduces them by $0.9 \%$. In the western basin the effects on a basin average are approximately $50 \%$ of the effects in the eastern basin, but the southern part is affected only weakly, as it is dominated by the properties of the inflowing Atlantic water. For both basins

\section{Currents 27m}

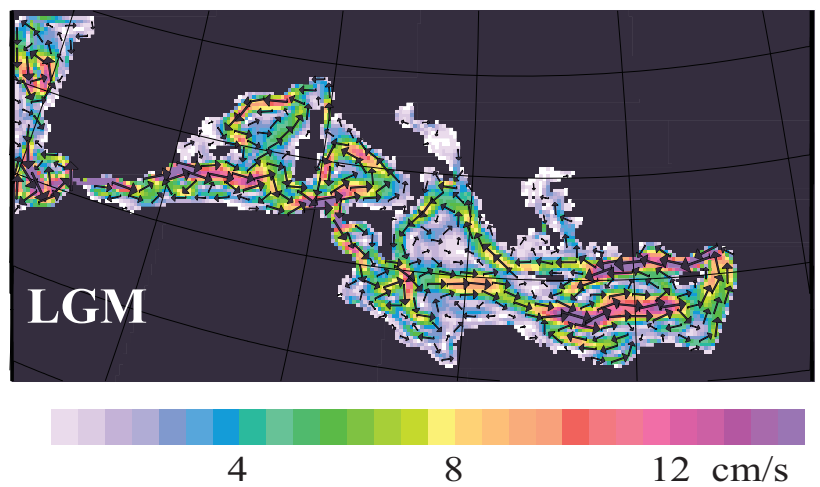

Fig. 13. Currents at $27 \mathrm{~m}$ depth for LGM. Colours indicate the flow speed in $\mathrm{cms}^{-1}$, vectors both direction and speed. Only a subset of vectors has been plotted. For CTL see Fig. 5

the salinity at depth strongly follows the changes in the eastern basin. The plume of the Nile discharge propagates in a cyclonic circulation near the coast around the Levantine. The consequence of a reduction of the Nile discharge is a reversed east-west salinity gradient in the eastern Mediterranean. The smaller the Nile discharge, the higher is the salinity gradient between the Rhodes gyre and the northern Ionian. With a doubled Nile discharge the gradient is reversed and the highest salinities are found in the Ionian. These changes in the salinity gradient have immediate consequences for the amount of LIW formed: whereas it is absent in simulation LGM-N2, it is strongly enhanced in simulation LGM-NO. In the latter simulation, a substantial amount of dense water is formed in the Aegean, but it is, when reaching the Levantine, not dense enough to form bottom water, it only penetrates to $1200 \mathrm{~m}$ depth. This, however, could be an artifact due to the model's difficulties to represent deep overflow plumes adequately. In run LGM-N0, the center of convection in the Ionian is shifted towards northeast. Deep convection occurs at the continental slope off western Greece. In run LGM-N0 the convection in the Tyrrhenian is strongly reduced due to the higher density of the water passing through the Strait of Sicily.

The anomalies in sea surface temperatures between these three LGM simulation (not shown) are generally small due to the formulation of the upper boundary condition for temperature. In experiment LGM-N0 the deep temperatures in the eastern basin are generally somewhat warmer due to the higher contribution of LIW. This effect is as large as $0.4 \mathrm{~K}$ on a basin average around $400 \mathrm{~m}$. In the western basin the entire deep part is warmer by 0.6 to $0.8 \mathrm{~K}$.

The circulation changes in experiment LGM-N0 with suppressed Nile discharge are much more similar to the circulation changes found in Myers et al. (1998) than the baseline LGM simulation, however, deep water formation in the northern Ionian is important in all LGM simulations. 


\section{Salinity and convection depth}
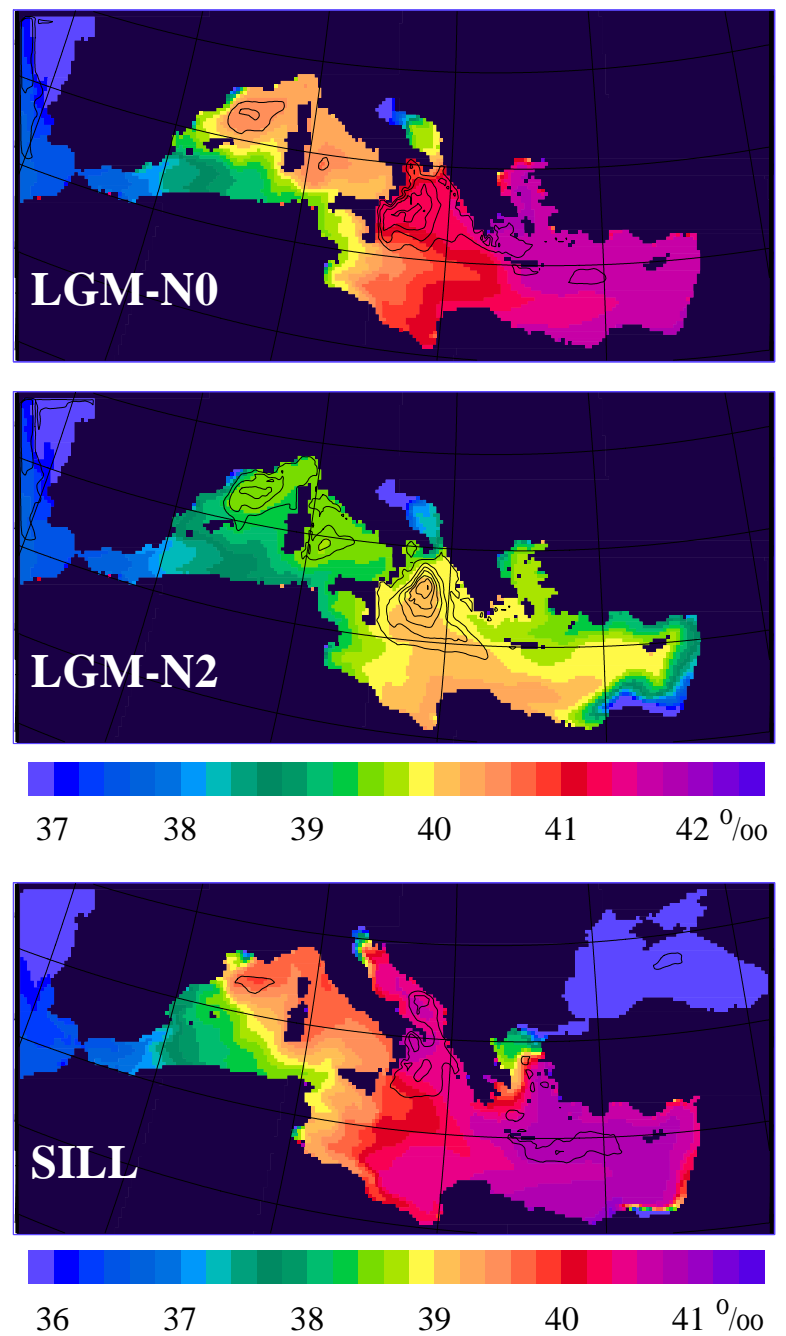

Fig. 14. Simulated annual mean surface salinity (colours, contour interval $0.2 \%$ ) and climatological maximum mixed layer depth (isolines, contour interval $250 \mathrm{~m}$ ) for sensitivity experiments. The panels show the LGM experiments with modified Nile discharge: suppressed (LGM-N0) and doubled (LGM-N2) Nile discharge and the present day sensitivity experiment with reduced sill depths in the Straits of Gibraltar and Sicily. Cf. Figs. 11 top and 3.

The outflow rates of Mediterranean water through the Strait of Gibraltar in the experiments LGM-NO, LGM and LGM-N2 are $0.43,0.40$ and $0.34 \mathrm{~Sv}$. The relation between deep westward flow through the Strait of Sicily and the net evaporation in the eastern Mediterranean is similar. The outflow rates in the three experiments are $0.69,0.63$ and $0.48 \mathrm{~Sv}$ with a net freshwater loss of the eastern Mediterranean in run LGM of $18900 \mathrm{~m}^{3} \mathrm{~s}^{-1}$. For both straits the model results suggest for the LGM $Q_{i} \propto E_{i}^{1 / 3}$, where $Q_{i}$ is the outflow through the strait and $E_{i}$ the net freshwater loss east of the respective strait.
In the sensitivity experiment SILL the effect of the lower sill depths in the LGM is investigated. The set up of this experiment is identical to run CTL except that the sill depths of the Straits of Gibraltar and Sicily are set to LGM values. This run was initialized from year 499 of CTL and integrated for 1300 years. The lowered sill depth of the Strait of Gibraltar resulted in a reduction of the Mediterranean outflow to $0.44 \mathrm{~Sv}$. The hydrological budget was almost unchanged. Due to the longer residence times, the salinity inside the Mediterranean increased (see Figs. 14). In the eastern basin the mean surface salinity increased by $1.8 \%$. The formation of LIW is increased compared to run CTL. In the western basin the reduced amount of inflowing Atlantic water penetrates further to the north than in CTL. The outflow through the Strait of Sicily of $1.07 \mathrm{~Sv}$ is similar to the outflow in the control simulation $(1.06 \mathrm{~Sv})$, but the separation between deep outflow and near-surface recirculation is less clear than in run CTL.

Variations in the flow through the Strait of Gibraltar due to changes in evaporation and sill depth between the different experiments show a similar relation, as would be expected by hydraulic control and the assumption of overmixing (see Eq. 5), although the flow - at least in the long-term mean - is subcritical.

\subsection{Effect of downscaling}

The approach to downscale the results from coarse resolution coupled atmosphere-ocean models using first an (often regional) high-resolution atmosphere model is rather standard. This high resolution atmopheric forcing can then be used to force a high-resolution ocean-only model. This approach has been used e.g. by Somot et al. (2006) to investigate future changes in Mediterranean ocean climate in response to anthropogenic climate change. The approach used here is essentially similar. This leads to the question, what additional information has been obtained by the downscaling.

The comparison of the SST anomalies simulated by the regional model (see Fig. 9) compared to the anomalies simulated by the coarse resolution ESM (see Fig. 15) shows quite some similarity, indicating that the response in SST is modified only to a small degree by the downscaling. The coarse resolution ESM (atmospheric resolution approx. $3.75^{\circ}$, ocean resolution in the Mediterranean between 180 and $250 \mathrm{~km}$ ) simulates essentially the spatial gradients in SST change between LGM and CTL found also in the regional model. The circulation changes in the atmospheric component are rather similar to the changes in the higher resolution model with enhanced inflow of cold and moist Atlantic air due to topographic forcing.

Due to the lack of resolution the changes in the exchange across the Straits of Gibraltar and Sicily are not reproduced well in the ESM's ocean component. Nevertheless, the ESM produces a larger gradient between Atlantic and Levantine 
SST anomaly LGM-CTL from ESM
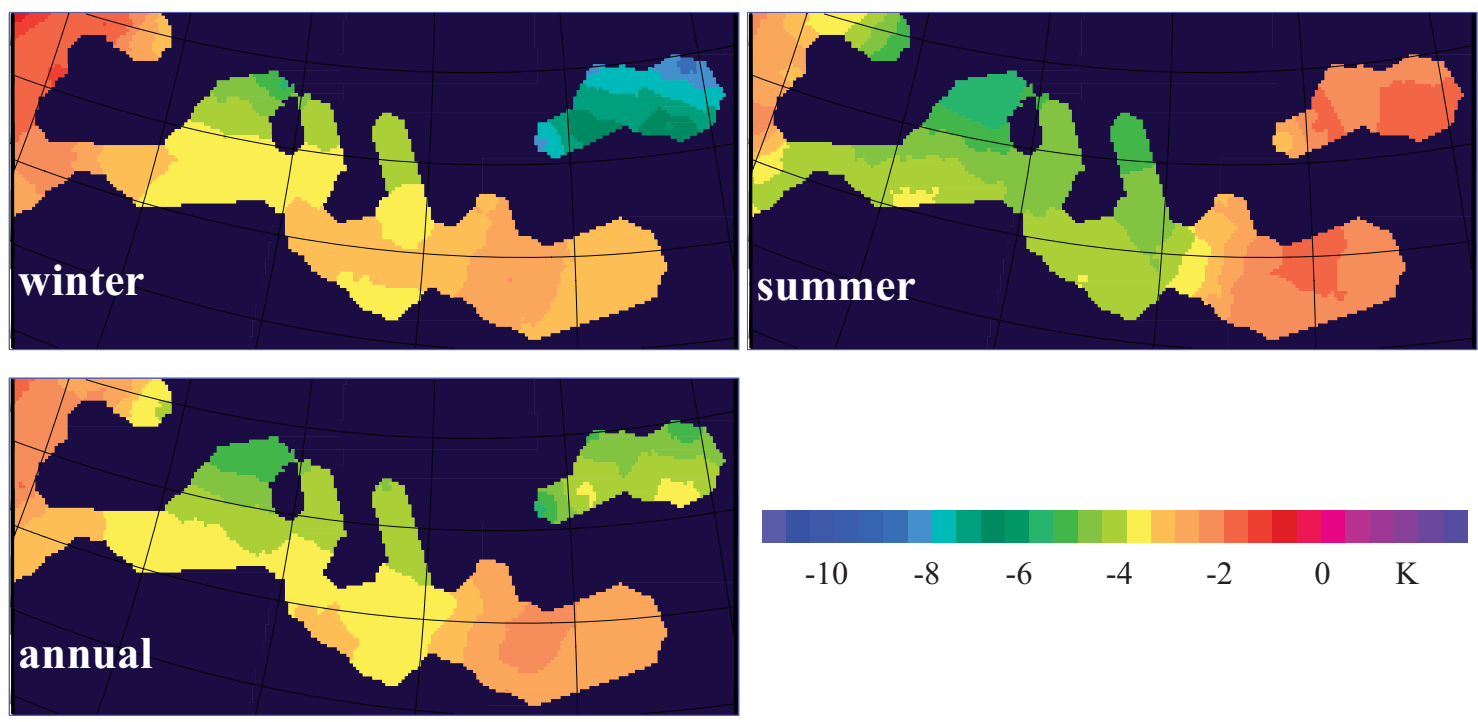

Fig. 15. Simuated SST anomalies LGM-CTL from the ESM in K. Winter (JFM), annual, and summer (JAS). The data have been interpolated onto the grid of the regional model. Cf. Fig. 9. The land sea mask has been interpolated from the ocean component of the ESM.

salinity during the LGM. Reliable estimates of changes in salinity, circulation and deep water formation inside the Mediterranean etc. are beyond the capability of the ESM. Here the downscaling with a regional ocean model definitely adds valuable information.

Attempts to force the regional ocean model directly with the atmospheric forcing from the ESM failed to produce a realistic ocean climate. Especially the wind stress forcing turned out to be a major problem preventing a realistic surface circulation inside the Mediterranean ocean. The use of a coupled regional atmosphere-ocean model, as has been done for the problem of anthropogenic climate change (e.g. Somot et al., 2008) could further increase the effective resolution, but the required spin-up times of more than 1000 years for LGM climate are prohibitively expensive. Periodicallysynchronous coupling techniques like the one applied by Mikolajewicz et al. (2007a) could help to circumvent this problem. The computationally expensive atmospheric model component is integrated only for part of the time. The stand-alone ocean component, which requires long integration times due to the inertia of the deep ocean, is integrated in the remaining time with fluxes derived from the fully coupled integration periods.

\section{Summary and conclusions}

With a chain of model simulations it was possible to reproduce the LGM ocean climate. Whereas the changes in the pattern of deep water formation in the western Mediterranean are moderate, the differences in eastern Mediterranean deep water formation are substantial. Deep convection in the LGM simulation is concentrated in the region east of Sicily, LIW formation in the Rhodes gyre is only weak. However, the changes in the eastern basin are strongly sensitive to the strength of the Nile discharge. In the LGM simulation the Adriatic is an estuarine basin, whereas it is the main source of deep water in CTL. The lowered sea level during LGM results in reduced sill depth for the Strait of Gibraltar. The consequence is reduced exchange across the sill, which in turn leads to stronger salinity enrichment in the Mediterranean in relation to the inflowing Atlantic water than at present, in spite of reduced net evaporation during LGM.

The model reproduces the pattern of Mediterranean surface temperature change between LGM and the present estimated from distributions of foraminifera, although the summer cooling in the Gulf of Lion is underestimated in the model. This pattern is almost entirely set by the simulation with the coarse resolution ESM. This can be explained by the temperature restoring, which is implicit in the use of calculating heat fluxes from bulk formulas with prescribed atmospheric input data and modeled SST. Only in regions with strong changes in air-sea heat exchange (like e.g. regions with deep convection or intense upwelling), substantial changes in SST can occur.

The strong summer cooling in the northwestern Mediterranean in LGM relative to the present can be explained by enhanced advection of cold and moist air of Atlantic origin across southern France. Whereas in the CTL simulation the vertical near-surface ocean temperature gradient is quite large in summer, the stronger winds and the associated enhanced vertical mixing at LGM substantially reduce this 
stratification, distributing the reduced summer warming over a larger depth interval. The consequence is a strong surface cooling between LGM and the present, but only a moderate cooling at the levels immediately below. This strong vertical gradient in the euphotic zone has so far not been accounted for in the reconstructions. Here, a consideration of the depth interval where the foraminifera actually are living, might improve the realism of the reconstructions. For consistent estimation of the climate change, the reference data set needs to be determined from core top data.

The presence of a small ice sheet or enhanced glaciation in the Alps in the ESM setup could have enhanced the cooling over land and thus amplified the episodic cooling by northerly winds. This would impose a strong additional cooling in the Gulf of Lion and a weak additional cooling in the western Mediterranean. This could also reduce the difference in the amplitude between the modeled and reconstructed summer SST in the northwestern Mediterranean. Additional improvement can be expected from ongoing LGM simulations with the latest generation of climate models.

Acknowledgements. This work was in part performed within the project HOBIMED, funded by the Deutsche Forschungsgemeinschaft within the cooperative project INTERDYNAMIK. The computations have been performed at the DKRZ. The motivation for this work arose from discussions with Michal Kucera. Comments from Fanny Adloff, Rosina Grimm, Alfredo Izquierdo, Ernst Maier-Reimer, Paul Meijer, Eelco Rohling, and an anonymous reviewer helped to improve this manuscript substantially. The paper was written during a visit at the Rossby Centre at SMHI. Selected data will be made available in the PANGAEA database after publication of the paper.

The service charges for this open access publication have been covered by the Max Planck Society.

Edited by: N. Weber

\section{References}

Aksu, A. E., Hiscott, R. N., and Yasar, D.: Oscillating Quaternary water levels of the Marmara Sea and vigorous outflow into the Aegean Sea from the Marmara Sea - Black Sea drainage corridor, Mar. Geol., 153, 275-302, 1999.

Alhammoud, B., Meijer, P. T., and Dijkstra, H. A.: Sensitivity of Mediterranean thermohaline circulation to gateway depth: A model investigation, Paleoceanography, 25, PA2220, doi:10.1029/2009PA001823, 2010.

Almogi-Labin, A., Bar-Matthews, M., Shriki, D., Kolosovsky, E., Paterne, M., Schilman, B., Ayalon, A., Aizenshtat, Z., and Matthews, A.: Climatic variability during the last $90 \mathrm{ka}$ of the southern and northern Levantine Basin as evident from marine records and speleothems, Quaternary Sci. Rev., 28, 2882-2896, 2009.

Arpe, K., Leroy, S. A. G., and Mikolajewicz, U.: A comparison of climate simulations for the last glacial maximum with three different versions of the ECHAM model and implica- tions for summer-green tree refugia, Clim. Past, 7, 91-114, doi:10.5194/cp-7-91-2011, 2011.

Baschek, B., Send, U., Lafuente, J. G., and Candela, J.: Intensive shipboard observations of the flow through the Strait of Gibraltar, J. Geophys. Res., 106(C12), 31017-31032, 2001.

Bethoux, J. P.: Budgets of the Mediterranean Sea: Their dependence on the local climate and on the characteristics of the Atlantic waters, Oceanol. Acta, 2, 157-163, 1979.

Bethoux, J. P. and Gentili, B.: Functioning of the Mediterranean Sea: Past and present changes related to freshwater input and climatic changes, J. Mar. Syst., 20, 33-47, 1999.

Bigg, G. R.: An ocean general circulation model view of the glacial Mediterranean thermohaline circulation, Paleoceanography, 9, 705-722, 1994.

Braconnot, P., Otto-Bliesner, B., Harrison, S., Joussaume, S., Peterchmitt, J.-Y., Abe-Ouchi, A., Crucifix, M., Driesschaert, E., Fichefet, Th., Hewitt, C. D., Kageyama, M., Kitoh, A., Laîné, A., Loutre, M.-F., Marti, O., Merkel, U., Ramstein, G., Valdes, P., Weber, S. L., Yu, Y., and Zhao, Y.: Results of PMIP2 coupled simulations of the Mid-Holocene and Last Glacial Maximum Part 1: experiments and large-scale features, Clim. Past, 3, 261277, doi:10.5194/cp-3-261-2007, 2007.

Bryden, H. L., Candela, J., and Kinder, T. H.: Exchange through the Strait of Gibraltar, Prog. Oceanogr., 33, 201-248, 1994.

Bryden, H. L. and Kinder, T. H.: Steady two-layer echange through the Strait of Gibraltar, Deep-Sea Res., 38, Suppl. 1, S445-S463, 1991.

Bryden, H. L. and Stommel, H. M.: Limiting processes that determine basic features of the circulation in the Mediterranean Sea, Oceanol. Acta, 7(3), 289-296, 1984.

D’Ortenzio, F., Iudicone, F., Montegut, C. D., Testor, P., Antoine, D., Marullo, S., Santoleri, R., and Madec, G.: Seasonal variability of the mixed layer depth in the Mediterranean Sea as derived from in situ profiles, Geophys. Res. Lett., 32, L12605, doi:10.1029/2005GL022463, 2005.

Emeis, K.-C., Struck, U., Schulz, H.-M., Bernasconi, S., Sakamoto, T., and Martinez-Ruiz, F.: Temperature and salinity of Mediterranean Sea surface waters over the last 16000 years: constraints on the physical environment of S1 sapropel formation based on stable oxygen isotopes and alkenone unsaturation ratios, Palaeogeogr. Palaeocl., 158, 259-280, 2000.

Emeis, K.-C., Schulz, H., Struck, U., Rossignol-Strick, M., Erlenkeuser, H., Howell, M. W., Kroon, D., Mackensen, A., Ishizuka, S., Oba, T., Sakamoto, T., and Koizumi, I.: Eastern Mediterranean surface water temperatures and $\delta^{18} \mathrm{O}$ composition during deposition of sapropels in the late Quaternary, Paleoceanography, 18(1), 1005, doi:10.1029/2000PA000617, 2003.

Farmer, D. M. and Armi, L.: Maximal two-layer exchange over a sill and through the combination of a sill and contraction with barotropic flow, J. Fluid. Mech., 164, 53-76, 1986.

Farrera, I., Harrison, S. P., Prentice, I. C., Ramstein, G., Guiot, J., Bartlein, P. J., Bonnefille, R., Bush, M., Cramer, W., von Grafenstein, U., Holmgren, K., Hooghiemstra, H., Hope, G., Jolly, D., Lauritzen, S.-E., Ono, Y., Pinot, S., Stute, M., and Yu, G.: Tropical climates at the Last Glacial Maximum: a new synthesis of terrestrial palaeoclimate data, I. Vegetation, lake-levels and geochemistry, Climate Dyn., 15, 823-856, 1999.

Hagemann, S. and Dümenil-Gates, L.: An improved sub grid runoff parameterization scheme for climate models, Climate Dyn., 21, 
349-359, 2003.

Hayes, A., Kucera, M., Kallel, N., Sbeffi, L., and Rohling, E. J.: Glacial Mediterranean sea surface temperatures based on planktonic foraminiferal assemblages, Quaternary Sci. Rev., 24, 9991016, 2005

Jaeger, L.: Monatskarten des Niederschlags für die ganze Erde, Ber. Dtsch. Wetterdienstes, 18, 138, 38 pp., 1976.

Jerlov, N. G.: Marine Optics. Elsevier Oceanography Series, Vol. 14, Elsevier, 231 pp., 1976.

Jost, A., Lunt, D., Kageyama, M., Abe-Ouchi, A., Peyron, O., Valdes, P. J., and Ramstein, G.: High-resolution simulations of the Last Glacial Maximum climate over Europe: a solution to discrepancies with continental palaeoclimatic reconstructions? Climate Dynamics, 24, 577-590, doi:10.1007/s00382-005-00094, 2005.

Kim, S.-J., Crowley, T. J., Erickson, D. J., Govindasamy, B., Duffy, P. B., and Lee, B. Y.: High-resolution climate simulation of the Last Glacial Maximum, Climate Dyn., 31, 1-16, 2008.

Kuhlemann, J., Rohling, E. J., Krumrei, I., Kubik, P., Ivy-Ochs, S., and Kucera, M.: Regional synthesis of Mediterranean atmospheric circulation during the Last Glacial Maximum, Science, 321, 1338-1340, doi:10.1126/science.1157638, 2008.

Lee, K. E: Compilation of alkenone LGM SST data, doi:10.1594/PANGAEA.103070, 2004.

Kohfeld, K. E. and Harrison, S. P.: How well can we simulate past climates? Evaluating the models using global palaeoenvironmental datasets, Quaternary Sci. Rev., 19(1-5), 321-346, 2000.

Lacombe, H. and Richez, C.: The regime of the Strait of Gibraltar, in: Hydrodynamics of Semi-Enclosed Seas, edited by: Nihoul, J. C. J., Elsevier, Amsterdam, 13-73, 1982.

Legates, D. R. and Wilmot, C. J.: Mean seasonal and spatial variability in guage-corrected, global precipitation, Int. J. Climatol., 10, 111-127, 1990.

Ludwig, W., Dumont, E., Meybeck, M., and Heussner, S.: River discharges of water and nutrients to the Mediterranean and Black Sea: Major drivers for ecosystem changes during past and future decades?, Progr. Oceanogr., 80, 199-217, 2009.

Maier-Reimer, E.: Design of a closed boundary regional model of the Arctic Ocean, Bull. Amer. Meteor. Soc.: Workshop on polar processes in global climate, 13-15 Nov, 1996, 72-73, 1997.

Malmgren, B. A., Kucera, M., Nyberg, J., and Waelbroeck, C.: Comparison of statistical and artificial neural networks for estimating past sea surface temperatures from planktonic foraminifer census data, Paleoceanography, 16(5), 520-530, 2001.

Mariotti, A., Struglia, A. V., Zeng, N. and Lau, K.-M.: The Hydrological Cycle in the Mediterranean Region and Implications for the Water Budget of the Mediterranean Sea, J. Clim., 15, 1674 1690, 2002.

Marsland, S., Haak, H., Jungclaus, J., Latif, M., and Roeske, F.: The Max Planck Institute global ocean/sea ice model with orthogonal curvilinear coordinates, Ocean Model., 5, 91-127, 2003.

Matthiesen, S. and Haines, K.: A hydraulic box model study of the Mediterranean response to postglacial sea-level rise. Paleoceanography, 18(4), 1084, doi:10.1029/2003PA000880, 2003.

MEDAR Group: MEDATLAS/2002 database. Mediterranean and Black Sea database of temperature salinity and bio-chemical parameters, Climatological Atlas, IFREMER Edition (4 Cdroms), 2002.

Mikolajewicz, U. and Maier-Reimer, E.: Mixed boundary condi- tions in ocean general circulation models and their influence on the stability of the model's conveyor belt, J. Geophys.1 Res., 99(C11), 22633-22644, 1994.

Mikolajewicz, U., Vizcaino, M., Jungclaus, J., and Schurgers G.: Effect of ice sheet interactions in anthropogenic climate change simulations, Geophys. Res. Lett., 34, L18706, doi:10.1029/2007GL031173, 2007.

Mikolajewicz, U., Gröger, M., Maier-Reimer, E., Schurgers, G., Vizcaino, M., and Winguth, A.: Long-term effects of anthropogenic $\mathrm{CO} 2$ emissions simulated with a complex earth system model, Clim. Dynam., 28(6), 599-633, doi:10.1007/s00382-0060204-y, 2007a.

Myers, P. G., Haines, K., and Rohling, E. J.: Modelling the paleocirculation of the Mediterranean: The Last Glacial Maximum and the Holocene with emphasis on the formation of sapropel S1, Paleoceanography, 13, 586-606, 1998.

Peltier, W. R.: Global glacial isostasy and the surface of the ice-age Earth: the ICE-5G (VM2) model and GRACE, Annual Review of Earth and Planetary Sciences, 32, 111-149, 2004.

Pickard, G. L. and Emery, W. J.:Descriptive physical oceanography, Pergamon Press, Oxford, 320 pp., 1990.

Pinardi, E. and Masetti, E.: Variability of the large scale general circulation of the Mediterranean Sea from observations and modelling: a review, Palaeogeogr. Palaeoecol., 158, 153-173, 2000.

Reeder, M. S., Stow, D. A. V., and Rothwell, R. G.: Late Quaternary turbidite input into the east Mediterranean basin: new radiocarbon constraints on climate and sea-level control, in: Sediment Flux to Basins: Causes, Controls, and Consequences, edited by: Jones, S. J. and Frostick, L. E., Geological Society of London, Special Publication, 191, 267-278, 2002.

Robinson, S. A., Black, S., Selwood, B. W., and Valdes, P. J.: A review of paleoclimates and paleoenvironments in the Levant and the eastern Mediterranean from 25000 to 5000 years BP: setting the envoronmental background for the evolution of human civilisation, Quaternary Sci. Rev., 25, 1517-1541, 2006.

Roeckner, E., Bäuml, G., Bonaventura, L., Brokopf, R., Esch, M., Giorgetta, M., Hagemann, S., Kirchner, I., Kornblueh, L., Manzini, E., Rhodin, A., Schlese, U., Schulzweida, U., and Tompkins, A.: The atmospheric general circulation model ECHAM5, Part I: Model description, Max Planck Institute for Meteorology, Hamburg, Report no. 349, 2003.

Rohling, E. J.: Environmental controls on salinity and $\delta^{18} \mathrm{O}$ in the Mediterranean, Paleoceanography, 14, 706-715, 1999.

Rohling, E. J. and Bryden, H. L.: Estimating past changes in the eastern Mediterranean freshwater budget using reconstructions of sea level and hydrography, Proc. K. Ned. Akad. Wet. Biol. Chem. Geol. Phys. Med. Sci., 97, 201-217, 1994.

Somot, S., Sevault, F., and Déqué, M.: Transient climate change scenario simulation of the Mediterranean Sea for the twentyfirst century using a high-resolution ocean circulation model, 27(851), 879, doi:10.1007/s00382-006-0167-z, 2006.

Somot, S., Sevault, F., Déqué, M. and Crepon, M.: 21st century climate change scenario for the Mediterranean using a coupled atmosphere-ocean regional climate model, Global and Planetary Change 63, 112-126, 2008.

Stein, M., Torfstein, A., Gavrieli, I., and Yechieli, Y.: Abrupt aridities and salt deposition in the post-glacial Dead Sea and their North Atlantic connection, Quaternary Sci. Rev., 1-9, doi:10.1016/j.quascirev.2009.10.015, 2009. 
Thiede, J.: A Glacial Mediterranean, Nature, 276, 680-683, 1978.

Thunell, R. C. and Williams, D. F.: Glacial-Holocene salinity changes in the Mediterranean Sea: Hydrographic and depositional effects, Nature, 338, 493-496, 1989.

Tolmazin, D.: Changing coastal oceanography of the Black Sea I, Northwestern shelf, Prog. Oceanogr., 15, 217-276, 1985.

Vörösmarty, C. J., Fekete, B. M., and Tucker, B. A.: Global River Discharge 1807-1991, RivDIS v1.1. Available from: http: //www.daacsti.ornl.gov//RIVDIS/guides/rivdis_guide.html, last update: June 2004, 1998.

Waelbroeck, C., Labeyrie, L., Duplessy, J., Guiot, J., Labracherie, M., Leclaire, H., and Duprat, J.: Improving past sea surface temperature estimates based on planktonic fossil faunas, Paleoceanography, 13(3), 272-283, 1998.
WOA: World Ocean Atlas 1998, Version 2, http://www.nodc.-noaa. gov/oc5/woa98.html, Tech. rep., NationalOceanographic Data Center, Silver Spring, Maryland, 1998.

Wu, H., Guiot, J., Brewer, S., and Guo, Z.: Climatic changes in Eurasia and Africa at the Last Glacial Maximum and midHolocene: reconstruction from pollen data using inverse vegetation modelling, Clim. Dyn., 29, 211-229, 2007.

Xie, P. and Arkin, P. A.: Global monthly precipitation estimates from satellite-observed outgoing longwave radiation, J. Clim., 11, 137-164, 1998. 